THE RELATIONSHIP BETWEEN PLAYFULNESS AND CREATIVITY OF JAPANESE PRESCHOOL CHILDREN

by

Satori Izumi Taylor

Dissertation submitted to the Faculty of

Virginia Polytechnic Institute and State University in partial fulfillment of the requirements for the degree of

DOCTOR OF PHILOSOPHY

in

Family and Child Development

APPROVED:

Cosby Steele Roger Chair

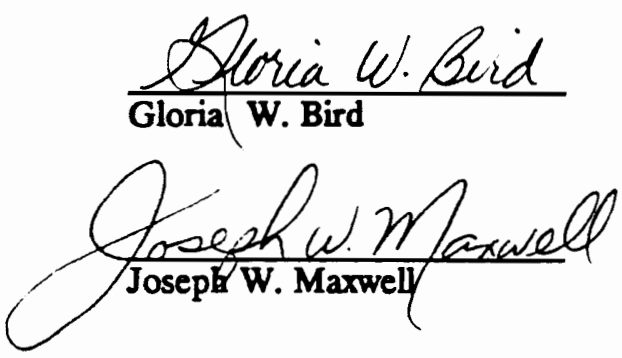

manly n V. Leet

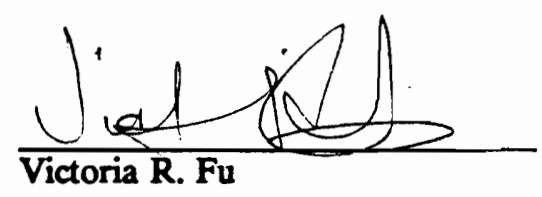

September, 1992

Blacksburg, Virginia 


\title{
THE RELATIONSHIP BETWEEN PLAYFULNESS AND \\ CREATIVITY OF JAPANESE PRESCHOOL CHILDREN
}

by

\author{
Satomi Izumi Taylor \\ Committee Chairperson: Cosby Steele Rogers \\ Family and Child Development
}

\begin{abstract}
(ABSTRACT)
A study of the relationship between playfulness and creativity was conducted with a sample of Japanese children who attended a preschool that emphasized whole-group orientation. Playfulness was assessed using The Child Behaviors Inventory, teacher interviews, and observations. Creativity was measured using The Creativity Thinking-Drawing Production Test (Jellen \& Urban, 1986), The Drawing Test (Acharyulu \& Yasodhara, 1984), teacher interviews, and observations. Although the statistical data analysis indicated no significant relationship between playfulness and creativity, the qualitative data analysis indicated that such a relationship may exist. However, conclusions must be qualified because analysis of the qualitative data revealed confounding factors in the concepts of playfulness and creativity. Some children who were rated by their teachers as nonplayful were described as internally playful and this internal playfulness was more evident in a one-to-one interaction and was manifest as joy, sense of humor, and active involvement. The internally playful child was described by the teachers as the child who possesses a lot of imagination inside but may not be able to express it externally in a group situation. Although the study focused on artistic creativity, the teachers in this study discussed a global view of creativity rather than artistic creativity. Thus, the results of qualitative data analysis appeared to contradict those of quantitative analysis. Further research on the relationship between playfulness and creativity is needed to understand such a relationship.
\end{abstract}




\section{Acknowledgments}

I would like to express my deepest appreciation to the following people who contributed to my research:

I am extremely grateful to Dr. Cosby Rogers who contributed her endless time, concern, support, advice, direction, encouragement, care, and guidance in pursuing my research. Without her support and devotion, this work would never have been finished.

I am also truly indebted to Dr. Marilyn Lichtman who took special interest in my study. Her insightful guidance, warm support, and constructive advice made my study possible.

I would like to thank Dr. Joseph Maxwell for his expert advice regarding narrowing down my research.

Special thanks to Dr. Gloria Bird and Dr. Victoria Fu for their support and interest in my study.

My special thanks also go to the director, the assistant director, and the teachers of Kawasaki Kindergarten in Japan, and the most of all, to the children who participated and cooperated willingly and enthusiastically in this experiment.

I would like to thank my former advisor, Dr. Violet Robinson, for her encouragement, support, and interest in my research. Her many phone calls from San Francisco kept me working hard throughout my research.

Many thanks to my friends, Jim and Doris Damiani, for their friendship, their warm support, the use of their laser printer, and the best home-cooked dinners interspersed throughout all stages of this research.

A heartfelt thanks goes to Bob Rogers who gave me many opportunities to use his beautiful office and excellent computer and laser printer.

I would like to especially thank my parents in Japan for their support, cooperation, and encouragement. 
Finally, I am grateful to my husband, John, for his unconditional support, encouragement, and confidence in me during my research. He is truly my best friend and partner. 


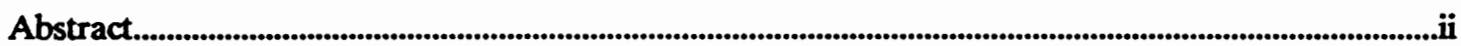

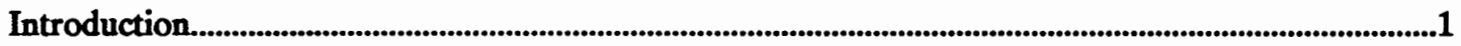

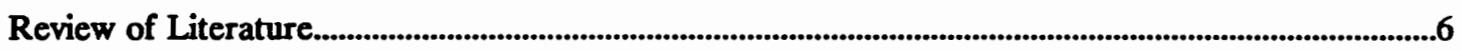

Japanese Educational Context.................................................................................................................................25

Methodology

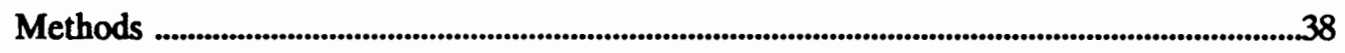

Data Collection

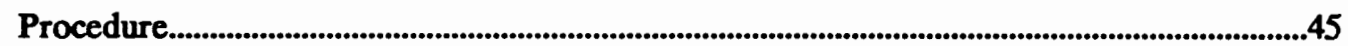

Data Analysis .........................................................................................................................................4

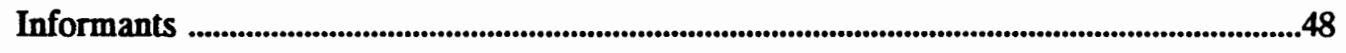

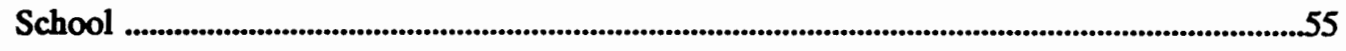

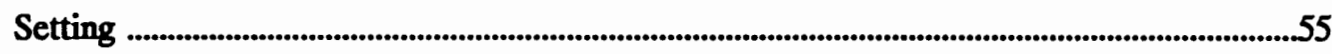

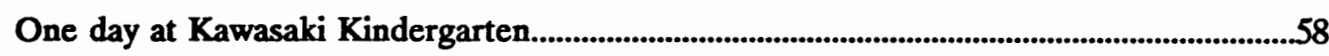

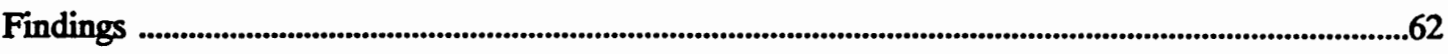

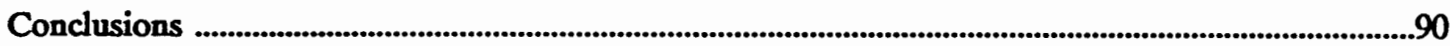

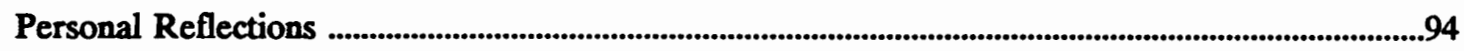

Limitations of the Study .......................................................................................................................................96

Recommendations for Future Research..............................................................................................97

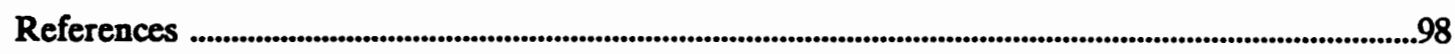

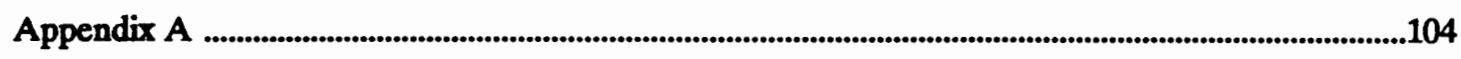

Appendix B ....................................................................................................................................................107

Appendix C ........................................................................................................................................................108 
Appendix D

.099

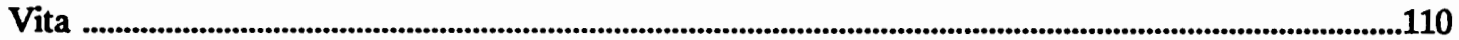




\section{LIST OF TABLES}

Table

Page

1. Means, Standard Deviations, and Statistical Tests by Class, Gender, and Age in CBI Scores. .63

2. T Test for TCT-DP Scores by Gender, Playfulness, and Age.. .65

3. T Tests for Drawing Test Scores by Gender, Age, and Playfulness.. .67 


\section{LIST OF FIGURES}

Figure

1. The Creativity Thinking-Drawing Production Test. . .41

2. The Creativity Thinking-Drawing Production Test Scoring Sheet. .43

viii 
The Relationship Between Playfulness and

Creativity of Japanese Preschool Children

\section{Introduction}

Creativity is the process of combining two or more things in a way that is novel either to the individual or to the society (Chambers, 1969). The elements being combined may be tangible or intangible; they may be verbal or nonverbal. As children respond to, act upon, and interact with their context, they create individual formulations of the self, the environment, and the relationship between the two (Csikszentmihalyi, 1988). In contrast, the products which are novel to a culture comprise artifacts of social, technological, and artistic achievement. In order for any society to evolve, the creative potential of individuals within the society must be facilitated (Csikszentmihalyi, 1988). Because of the importance of creativity to the development of any society, many scholars have observed, recorded, and speculated on the factors which contribute to its development. Factors studied include behavioral, contextual, and personality variables associated with creativity.

While some scholars have argued that creativity is a special mode of thinking with which only a small percentage of persons are endowed (e. g., Dudek, 1974), others have assumed the position that every individual has the potential for some degree of creativity (e.g., Torrance, 1977). In the second view, the degree of creative potential achieved is largely determined by the active synthesis of novel combinations arising from accumulative experience and knowledge in a context which supports the creative process.

Regardless of whether creativity is viewed as a process experienced by individuals or as products which are original contributions to society, both perspectives assume the importance of creativity. Therefore, much attention has been given to the identification of the factors that enhance creative potential. One such factor is play. Kogan (1983) stated that "...the research directed toward the issue 
of the play-creativity linkage may well represent the most promising set of findings in children's creativity literature over the past decade" (p. 624).

The contribution of play to creativity has been a common theme in studies on the behavioral, contextual, and dispositional influences on creativity. Substantial evidence for a relationship between play and creativity in terms of behavioral and contextual influences has been reported by many researchers (e. g., Dansky, 1980a, 1980b; Dansky \& Silverman, 1973, 1975; Pepler \& Ross, 1981; Singer \& Rummo, 1973). One dimension of play that has received less attention is the dispositional aspect-playfulness.

Playfulness, as a personality disposition, stands out in the literature describing highly creative individuals (John-Steiner, 1985; Lieberman, 1965). In the United States, Albert Einstein (John-Steiner, 1985), Thomas Edison, and Henry Ford who were known for their creative contributions to society, were highly playful individuals. Likewise, artists such as Picasso (John-Steiner, 1985) and Salvador Dali were also playful. A few researchers (Barnett \& Kleiver, 1982; Lieberman, 1965; Tegano, 1990) conducted empirical studies on the measurement of the disposition of play (e.g., playfulness) and its relationship to creativity.

Rogers (1988) defined playfulness as a trait characterized by the six dispositions described by Rubin, Fein, and Vandenberg (1983). The six dispositions are intrinsic motivation, process orientation, organism domination, nonliterality, relative freedom from externally imposed rules, and active involvement. Based on these criteria, Rogers (1988) developed a trait-rating instrument called the Child Behaviors Inventory to assess children's playfulness. To date only one researcher (Tegano, 1990) has used this instrument to assess the relationship between playfulness and creativity and her study focused on the relationship of playfulness to creativity in adults aged from 20 to 55 years old.

Lieberman (1965) and Barnett (1990) defined playfulness as physical, social, cognitive spontaneity, manifest joy, and sense of humor. Using this definition, significant relationships between playfulness and divergent thinking in children were reported by Lieberman (1985) and Barnett and 
Kleiver (1982). However, these studies tended to focus only on middle-class American children. To generalize and apply these results to other cultures would not be appropriate.

One culture which provides an interesting contrast to Western studies is that of Japan. Comparative studies of American and Japanese educational methods and outcomes have captured the attention of Western researchers recently (e. g., Bacon \& Ichikawa, 1988; Lewis, 1984, 1986a; Stevenson, Lee, Stigler, Kitamura, Kimura, \& Kato, 1986; Stigler \& Stevenson, 1991; White, 1984). The image that has emerged is one of a highly structured "non-play" orientation. However, these studies were conducted primarily with school-age children. The philosophy which guides formal schooling after the age of 7 years stands in sharp contrast to that of the Japanese preschool. For example, according to Bacon and Ichikawa (1988) and Tobin, Wu, and Davidson (1989a), Japanese preschools are more play-oriented than are American preschools.

In addition to the Japanese preschools subscribing to play-oriented programs, they strongly emphasize group orientation in the classroom. This does not mean, however, that individual achievement is discouraged as teachers and children know well the talents and abilities of each member of the group (Hendry, 1986a). In Hendry's words,

It is part of the role of the kindergarten to develop creativity, self-reliance, and selfawareness in their charges, and the teachers are in regular communication with the parents about each child's progress. Individuality is important, but it must develop within the limits imposed by being a member of a group. (p. 56)

Both Japanese and American educators have hypothesized that play promotes creativity. However, the approaches to promoting creativity are different. In the United States emphasis is placed upon individual creativity, whereas in Japan, more attention is given to creativity within a group (Hendry, 1986a). In the United States, there also exists a preponderance of competition against others on an individual level. In Japan on the other hand, because there is a great emphasis on group activity and cooperation, competition exists primarily as a competition between groups. Group competition has the 
advantage of having the individual feel less the sting of defeat as the individual loss is diffused in a group situation (Johnson \& Johnson, 1989). In the cooperative group activity, all those involved are working together toward a common goal. Rather than isolating the individual's ideas, thoughts are brainstormed and compounded. In my personal conversation with E. Paul Torrance in October of 1987, he suggested that creativity is at its highest when members of a group cooperate to accomplish a given task.

Because Japanese education has as one major goal the transition of the accumulated wisdom of the culture, an exploration of Japanese early childhood education could offer a salient contribution to understanding creativity in the context of a group-oriented society. Exploring how Japanese playoriented preschools or kindergartens nurture children's creativity in the context of groupism (a term used by Tobin et al., 1989a) will contribute to our understanding of the relationship between playfulness and creativity in a setting which has not been studied previously.

Creativity manifests itself in various ways and can be expressed in writing, art, music, science, and so on. Children's creativity can be seen especially in their drawings as children are adept at expressing their feelings and thoughts in this way (Gardner, 1973; Kinsey, 1984). According to Kinsey (1984), creative children seem to use drawing as a primary means for expressing their imagination or fantasies. Because of its capacity to reflect and influence culture, artistic creativity will be the focus of this study.

\section{Research Questions}

My research questions are concerned with two areas regarding the relationship between playfulness and creativity of Japanese children:

1. Is there such a relationship among a sample of Japanese children attending a play-oriented preschool?

2. In what way does the context of the preschool classroom climate in Japan influence such a relationship?

In summary, both Japanese and American educators have hypothesized that play promotes creativity and some Western studies found significant relationships between playfulness and creativity. 
Since Japanese preschool methodology encourages play and creativity in the context of group orientation, exploring the relationship between playfulness and creativity of Japanese children will enhance and stimulate our understanding of such a relationship in terms of a group-oriented environment. 


\section{Chapter 1}

\section{REVIEW OF LITERATURE}

The purpose of this study was to investigate the relationship between playfulness and creativity among a sample of Japanese preschool children. Theoretical and empirical literature on both playfulness and creativity and the link between the two will be reviewed in order to establish the background for the study. Artistic creativity is the focus of the study and, therefore, particular attention will be given to research on the relationship between playfulness and artistic creativity.

\section{Creativity}

\section{Theories of Creativity}

Theories of creativity can generally be classified according to theorists' definition of creativity and explanations of its development. While some theories focus on cognitive features of the creative process (e. g., Guilford, 1956; Sternberg, 1988; Torrance, 1973; Vygotsky, 1930/1990), others (e. g., Rogers, 1962; Wallace \& Kogan, 1965) focused on the context for creative expression. Both types of theories will be reviewed.

\section{Copnitive Approaches}

Vygotsky. According to Vygotsky (1930/1990), children's play is an early form of creativity. Play of children is creative because it recreates past experiences into new realities rather than simply reproducing reality. The play activity of the child is more than recollecting past experiences; it includes a creative recombination of impressions upon which the child constructs new realities that address his or her needs. Vygotsky distinguished between reproductive imagination and combinatory or creative imagination by stating that reproductive imagination is closely related to one's prior experiences or memory, while combinatory imagination creates new forms or activities by combining experience in new ways and is also related to one's ability to deal with change. Vygotsky called the combinatory ability imagination or fantasy (1930/1990). According to his perspective, creativity exists when one's 
imagination combines, changes, and creates something new, and imagination is the basis of any creative activity. It is also part of all cultural life, such as art, science, and technological innovation.

According to Smolucha and Smolucha (1986a), Vygotsky defined imagination as the internalization of children's play. Just as egocentric speech becomes inner speech, children's play becomes internalized in imagination. The function of play is both social interaction and direction of one's thoughts and actions. Imagination has its origins in socialization and differentiates into a vehicle for wish fulfillment or creative problem-solving in art and science (1930/1990).

Because Smolucha translated Vygotsky's work into English and studied his creativity theory in terms of play, her work is helpful in understanding Vygotsky's theory of creativity. Smolucha (1988) explained that in Vygotsky's theory, imagination is based upon reality and is a necessary part of any creative activity. The basis of Vygotsky's theory of creative imagination consists of four factors: "...imagination develops from children's play, it becomes a higher mental function, in adolescence imagination collaborates with reason, and imagination is an integral part of adult artistic and scientific creativity" (Smolucha, 1988, p. 95).

Smolucha (1989) claimed that creative imagination develops from children's play into a higher mental function that can be regulated through inner speech. Therefore, the development of inner speech relates to the development of imagination (Smolucha \& Smolucha, 1986b). Imagination and inner speech come about as a result of social interactions and become internalized at about the age of 7 years. Thus, children learn pretend play through interacting with adults and those interactions influence children's development and imagination (Smolucha, 1986b). The preschooler's symbolic play has both an external and an internal function. The former is social and reality related, whereas the latter directs and organizes mental images.

Guilford. According to Guilford (1956), the intellectual factors consist of two major groups (thinking and memory factors), and the majority of them are thinking factors. He divided thinking factors into three components: (a) cognition (discovery factors), (b) production factors, and (c) 
evaluation factors. The production factors can be subdivided into convergent-thinking and divergentthinking abilities. The factors in each group were arranged by three kinds of content (figural, structural, and conceptual).

The cognition factors, according to Guilford, are related to one's awareness of mental items or constructs of one kind or another. In Guilford's (1956) words, "In the tests of these factors, something must be comprehended, recognized, or discovered by the examinee. They represent functions on the receiving side of behavior sequences" (p. 269).

Convergent thinking is associated with the production of an end result. After one has understood the situation or the important parts of it, one usually tries to act upon it. For example, in the analogies test, Guilford (1956) stated that "...having seen the relation between the first pair of elements of an item we must then find a correlate to complete another pair. Having understood a problem, we must take further steps to solve it" (p. 274).

In divergent thinking, there are three types of content (figural, structural, and conceptual). In these three types of content, Guilford (1956) delineated word fluency, associational fluency, ideational fluency, expressional flexibility, spontaneous flexibility, originality, and elaboration. In the tests of word fluency, meaning is not important but a structural requirement is needed. In other words, "The usual tests of this factor merely specify that the words shall begin or end with a specified letter, prefix, or suffix" (p. 297). In the case of associational fluency, meaning is required. In ideational fluency, one's ability to have ideas is tested. In the tests of expressional-fluency, one's ability to put ideas into words is tested.

Three kinds of flexibility were described by Guilford (1956): (a) flexibility to closure, (b) adaptive flexibility, and (c) spontaneous flexibility. Flexibility to closure and adaptive flexibility comprised a common factor owing to the finding that perceptual, structural, and conceptual scores had strong loadings on the same factor. This factor cuts across all three kinds of context (figural, structural, and conceptual). 
In the tests of spontaneous flexibility, tasks measure the tendency to reactive inhibition. In originality tests, one's unconventional, clever, or remotely associated responses are tested. In the elaboration factor tests, the ability to provide details working toward completion is tested.

Guilford also indicated that some divergent-thinking processes tend to occur in non-realistic thinking when one is allowed freedom to associate freely. Creative thinking and problem solving depend on different combinations of factors and the combination of factors important to the task might differ from time to time.

Wallace and Kogan. Wallace and Kogan (1965) defined the creative process as: "...first, the production of associative content that is abundant and that is unique; second, the presence in the associator of a playful, permissive task attitude" (p. 289). In assessing creativity, a playful gamelike context with freedom from time limitation is important so that one does not feel the pressure of success or failure. In other words, previous work on the assessment of creativity tended to focus on a successfailure criterion. However, Wallace and Kogan asserted that a playful attitude in a task-centered environment may be more appropriate for supporting creativity.

In an effort to delineate the etiology of creativity and the contribution of individual behavioral dispositions to creativity, Wallace and Kogan (1965) studied the presence of creativity in children of both high and low intelligence. The subjects of their study were 151 children in the fifth grade from middleclass families. For two weeks the children were observed in their school environments and were rated on Wallace and Kogan's behavior scale. After administering seventeen procedures to the children, Wallace and Kogan were able to identify groups of children separated by gender who were creative and intelligent, creative but not intelligent, intelligent but not creative, and neither intelligent nor creative.

Wallace and Kogan found that highly creative and highly intelligent boys tended to have interpersonal sensitivity and were aware of their own integrity and identity. The boys who were high in creativity but low in intelligence seemed to be defensive and were angry over their own inadequacies. The boys with high intelligence but low creativity seemed to have an overriding concern with academic 
success and were concerned with how they were viewed by adults. The boys who were low in both intelligence and creativity tended to give up or avoid academic activities. Some were hyperactive and tended to seek comfort from sympathetic adults.

The girls who were high in both creativity and intelligence appeared to have strong powers of integration, accompanied by the ability to roam about freely and imaginatively and with enthusiasm. They also displayed high levels of social awareness and sensitivity to others' emotional expression. The highly creative girls with low intelligence appeared to react negatively to school pressure. They seemed to be angry and resentful toward the school setting; however, free and even wild imaginings were found among these girls. The girls who were high in intelligence and low in creativity seemed to be motivated toward academic achievement in order to avoid feeling badly. The girls low in both intelligence and creativity gave evidence of trying to work within the confines of their poor intellectual performance. These girls appeared not to know how to cope successfully with their academic tasks, and their frustration and depression over academic failure were evident.

In the case of the high intelligence-low creativity child, Wallace and Kogan postulated that exposure to a gamelike or playful context in assessing creativity would provide a cognitive play experience rather than a success-failure experience. Wallace and Kogan asserted that a playful task attitude supports the development of cognitive skills and expansion of creative abilities. Thus, when aduits focus less on success and failure and more on a playful approach to children's school work, much can be gained (Wallace \& Kogan, 1965).

Rogers. Carl Rogers (1962) defined the creative process as "the emergence in action of a novel relational product, growing out of the uniqueness of the individual on the one hand, and the materials, events, people, or circumstances of his life on the other" (p. 65). Rogers delineated the inner conditions of constructive creativity as: (a) openness to experience, (b) an internal locus of evaluation, (c) the ability to toy with elements and concepts, and (d) psychological safety and freedom. Openness to experience requires a lack of rigidity, a tolerance for ambiguity, and the ability to accept conflicting 
information. An internal locus of evaluation requires self-evaluation rather than dependency on approval from others. The ability to toy with elements means that one's spontaneous toying and exploration provide new and significant ways of seeing life.

In psychological safety, acceptance of the individual by others as having unconditional worth fosters his/her creativity, according to Rogers (1962). When one learns in a climate of safety, the self can be regarded as worthwhile regardless of the quality of the performance. Thus, one can discover selfmeaning and develop creativity. Providing a nonjudgemental climate is an important component in psychological safety. In Rogers's words (1962), "When we cease to form judgments of the other individual from our own locus of evaluation, we are fostering creativity" (p. 70). In addition, empathic understanding is an important component of psychological safety. An unconditional acceptance or understanding of the individual fosters creativity. When one's point of view or feeling is accepted and understood by others, the real self can emerge and be expressed in a variety of ways. In psychological freedom (Rogers, 1962), when one has permission for complete freedom of symbolic expression, creativity is fostered. In his words:

This permissiveness gives the individual complete freedom to think, to feel, to be, whatever is most inward within himself. It fosters the openness, and the playful and spontaneous juggling of percepts, concepts, and meanings, which is a part of creativity.

Rogers further explained that permissiveness is not softness or induigence, nor encouragement, but rather the permission to be free and responsible. Freedom and responsibility to be oneself fosters the development of a secure locus of internal evaluation and, thus, tends to bring about the conditions of constructive creativity.

Sternberg. According to Sternberg (1988), the intellectual facet of creativity can be understood by (a) its relation to the internal world of the individual, and (b) experience and the external world of the individual. In the relation of intelligence to the internal world, creativity can be understood by 
examining the processes of the intellect. The relevant processes include metacomponents, performance components, and knowledge-acquisition components.

Metacomponents (Sternberg, 1988) are higher-order processes used in planning, monitoring, and evaluating problem solving. In metacomponents, recognizing the existence of a problem is important. Thus, defining a problem and formulating a strategy and mental representation for problem solving are vital parts of metacomponents. Performance components of intelligence execute the instructions of the metacomponents. Knowledge-acquisition components involve three different kinds of potentially creative insights: (a) selective encoding, (b) selective combination, and (c) selective comparison. Selective encoding involves "knowing which pieces of information are relevant" (Sternberg, 1988, p. 136), and selective combination involves "knowing how to blend together the pieces of relevant information" (p. 136). Selective comparisons refer to relating newly obtained information to existing information, for example, problem-solving by analogy.

In the relationship of intelligence to experiences, the components of intelligence can be applied to solve problems at various levels of experience (Sternberg, 1988). This happens, for example, when the individual realizes how to apply knowledge to a new task or situation. Working with novelty provides the opportunity to display creativity. In the relation of intelligence to the external world, creativity has a contextual element. In Sternberg's words, "Creativity is probably most associated with environmental shaping. The great thinkers in almost any field are those who shape the field to their own conception of what that field should be" (p. 138). For example, he pointed out that Hemingway, Dewey, and Picasso were considered to be creative because they were influential in shaping their respective fields.

Sternberg (1988) postulated that two important factors which contribute to creativity are intellectual styles and personality. Intellectual styles can be understood by examining Sternberg's theory of mental self-government. The mental self-government theory consists of five major factors: functions, forms, levels, scopes, and learning. Certain personality attributes are more conducive to creativity than 
are others. Among these are a tolerance of ambiguity, a willingness to surmount obstacles, a willingness to grow, intrinsic motivation, moderate risk-taking, a desire for recognition, and a willingness to work for recognition. Sternberg concluded that "...creativity is a multifaceted phenomenon, of which three critical facets would seem to be aspects of intelligence, styles, and personality" (p. 146-147).

Torrance. Torrance (1977) defined creativity as "the process of sensing problems or gaps in information, forming ideas or hypotheses, and communicating the results" (p. 6). This process may lead to various products including those having verbal/nonverbal or concrete/abstract qualities. Creativity is associated with the contributions of new and original ideas, different points of view, or new perceptions of problems. Torrance (1977) claimed that some degree of creativity occurs whenever problems are solved and the individuals "...go beyond where they have ever gone before" (p. 6).

According to Torrance (1977), when creativity is defined as a product, the results of the process may be an invention, a scientific theory, a literary work, a musical composition, or a new design. In the child's creativity, it may be the child's discovery of a new relationship in nature, a story, or a song.

He also purported that creative thinking is related to a number of abilities, such as fluency (the ability to come up with a large number of ideas), flexibility (the ability to use a number of approaches), originality (the ability to produce new ideas), elaboration (the ability to fill in the details), and redefinition (the ability to perceive in a new way).

In summary, theories of creativity by Vygotsky, Guilford, Wallace and Kogan, Rogers, Sternberg, and Torrance were discussed. Vygotsky considered play an early form of creativity. Guilford, Sternberg, and Torrance described creativity as a mental function, while Rogers, and Wallace and Kogan focused on the context in which creative expression can occur.

\section{Artistic Creativity}

While there are many modes of creative expression, one which often reflects and extends the culture of the creator is artistic creativity. Artistic creativity is related to one's sensibilities that make aesthetic awareness of the world possible. Gardner (1973) defined art in the following way: 
Every art form involves communication on the part of one person (or subject) to another by means of a symbolic object that the first subject has created, and that the second is able in some way to understand, react to, or appreciate. (p. 30)

Gardner's definition of art encompasses a broad spectrum of products regarded as an art form (from cooking to chess). The media of communicatory symbols are varied and can range from music, to painting, to motion pictures. Gardner pointed out that the aesthetic tends not be translatable. In other words, art is not easily translated into another symbol system. It stands on its own merit. Art reflects an essential desire to express feelings, thoughts, or beliefs through symbolic media.

According to Gardner (1973), the development of aesthetic processes consists of three systems: the feeling, making, and perceptual systems. The feeling system relates to affect, the making system is associated with action, and the perceptual system is equal to discrimination or distinction. He suggested that these three systems are independent at birth but they become interdependent as the child develops. Art and Play

Gardner (1973) claimed that art tends to focus on integration and organization of experience in a more comprehensive way. He classified art as one form of play.

...art is a goal-directed form of play. Play differs from the arts in its source and in its ultimate fate...While play is an amplification of all experience, the arts are restricted to a certain form of interpersonal communication for which specific symbolic media are suited. Perhaps we should think of play as a necessary antecedent for participation in the aesthetic process. (p. 166)

In addition to suggesting that play may be a necessary process for children to develop aesthetic skills, Gardner (1973) suggested that children's artistic work is related to emotions, personality, heredity, and temperament. Especially in drawing, children can express feelings, thoughts, and ideas (Eisner, 1982; Kinsey, 1984). 
Eisner (1982) considered that some artistic thinking is inherent in some individuals and that through art children learn about the world itself. Art, in his view, is a source of aesthetic experience. He described nine factors which promote the child's ability to think and perceive.

1. Through art children learn that they can create images with materials and that the art activity can provide intrinsic forms of satisfaction.

2. Children learn that the images they create can function as symbols.

3. Children learn that symbolic images can be transported into a fantasy world of symbolic play.

4. Children learn through image-making that this process requires judgements.

5. Children learn that images can be associated with other images to form a whole.

6. Through art children learn to develop skills of creating illusion and of forming images.

7. Through making images children learn that ideas and emotions which are not physically present can be expressed by symbols.

8. Children learn the fact that there are ideas, images, and feelings that can only be expressed by visual art forms.

9. Children learn though art that the world itself can be considered as a vital source of aesthetic experience.

Cottle (1973) defined artistic creativity as the ability to control and shape one's expression. He stated that, "Creativity involves the capacity to work spontaneously with human impulses and aspects of external reality and to apply one's own imagination and impulses onto reality--through a means of expression such as drawing" (p. 162).

\section{Conditions that Enhance Creativity}

The conditions which contribute to the development of artistic creativity are intrinsic motivation (Amabile \& Gitomer, 1984), sensitivities to the world (Gardner, 1973), material availability, stimulus and encouragement by adults and support of the art activity by parents and adults (Kinsey, 1984). 
Amabile (1982) stated that according to the intrinsic motivation hypothesis of creativity, external control of children's art performance can diminish their creativity. She stated that intrinsic motivation may be more conducive to creativity than extrinsic motivation. The highly creative state might be a deep level of involvement in the task with a sense of enjoyment and intellectual playfulness.

Kinsey (1984) asserted that children use drawing for the manipulation and communication of ideas. In Kinsey's words, "A drawing is infinitely malleable responding to thought, growing and developing with the thought" (p. 111). He suggested that in order to develop children's artistic creativity, materials should be available and adults should be available to talk about the children's art work. He claimed that drawing is the graphical communication of ideas and is such an important skill that every child should experience it.

\section{Measurement of Children's Art Products}

Some researchers measured children's art products to assess their creativity (Amabile \& Gitomer, 1984; Runco, 1989). Amabile and Gitomer (1984) measured preschoolers' artistic creativity under two conditions: the choice condition and the non-choice condition. The subjects were 28 children ranging in age from 2 to 6 years. Half of the subjects were asked to make collages using any materials they wished and the other half had no choice of materials. Using their own subjective definition of creativity, artists were asked to independently rate the collages. They found that the extrinsic constraint of the no-choice condition in task materials led to lower levels of creativity than the allowance of the choice condition.

Runco (1989) measured the creativity of children's art using artists' ratings. Children $(n=104)$ in grades 4 through 6 were asked to work on certain projects (a crayon drawing, a collage, and a large picture). Five professional artists judged these children's creativity using their own definition of creativity. Interrater and inter-item reliability estimates were used to calculate the true variance of rating. His study indicated that ratings by professional artists were relatively reliable. 
In summary, artistic creativity reflects and occasionally extends the culture of the creator. Art is a form of communication and children can express feelings, thoughts, and ideas through art, especially through drawing. Art is also a form of play and play may be a necessary process for children to develop aesthetic skills. Aesthetic creativity can be fostered by intrinsic motivation, material availability, and stimulation and encouragement by adults. Some researchers measured children's creativity by using professional artists' ratings of the children's art products.

\section{Measurement of Creativity}

Creativity has been measured by a variety of methods including (a) drawing or art products, (b) two- or three-dimensional materials, (c) visual stimulus materials, etc. Amabile and Gitomor (1984) and Acharyulu and Yasodhara (1984) measured children's creativity by assessing spontaneous drawings and use of ratings by professional artists of the children's art products.

Wallace and Kogan (1965) used visual stimulus materials such as the line game to measure children's creativity. In the line game, pictures of lines as single continuous units taking different shapes were displayed and children were asked to generate meanings or interpretations relevant to the form of each line in question. Starkweather (1971) measured children's originality using an instrument comprised of three-dimensional objects of various shapes. In this test children were asked to generate responses as to what each shape might appear to be.

Moran, Milgram, Sawyers, and Fu (1983) incorporated the use of materials adapted from those of Starkweather (1971), Wallace and Kogan (1965), and Ward $(1968,1969)$, in which preschool children responded to verbal stimuli (pictures of designs in patterns) presented on cards, and also provided possible interpretations of the pictures. In a test called "instances", the children named instances of a category, such as round things, things that make noise, and red things. In the verbal test, the children named uses of common objects, such as boxes, paper, and spoons. Moran et al. concluded that preschoolers were capable of generating original responses. 
Starkweather $(1964,1971)$ offered several arguments about the creativity tests existing at the time. First, she argued that the study of preschoolers' originality began with an exploratory use of materials designed for older children. Materials and approaches used with older children were not suitable for young children because young children's originality is not yet differentiated. Arguing that young children want to handle materials, she pointed out that this was precluded by the two-dimensional materials available, and that three-dimensional materials were needed for children to touch and handle. To overcome these problems, Starkweather (1971) developed a test comprised of simple threedimensional objects of various shapes made of plastic foam. Using these materials, Starkweather found that, while the originality scores required verbal responses, the scores were independent of verbal ability. She demonstrated this finding by analysis of originality scores and scores earned on the Peabody Picture Vocabulary Test. The correlation between the two sets of scores was not significant; therefore, Starkweather accepted the originality test as independent of verbal ability.

Starkweather's arguments have been supported by several studies (Fu, Kelso, \& Moran, 1984; Moran, Milgram, Sawyers, \& Fu, 1983; Moran, Sawyers, Fu, \& Milgram, 1982) which found that preschoolers generated more responses when they were allowed to handle the three-dimensional stimuli designed by Starkweather. These studies also found that three-dimensional materials were more appropriate than two-dimensional materials for measuring original thinking in preschool children. Using several tasks from the Starkweather Originality Test, these researchers found that preschoolers were capable of generating original thinking.

\section{Cross-Cultural Comparison of Creativity}

\section{Between Children in Japan and the United States}

Few studies have compared the differences in creativity between children in Japan and the United States with the exception of two studies done by Torrance and Sato (1979a, 1979b) comparing Japanese and American students' creative thinking and styles of thinking. The first study undertaken by Torrance and Sato was to compare the measurements of figural creative thinking abilities of 200 
Japanese and 200 American college students. The instrument of this study was the figural portion of the "Demonstrator Form of the Torrance Test of Creative Thinking" (1979). The test consisted of two incomplete figures and nine triangles. The subjects were asked to come up with pictures that no one else would think of from the incomplete figures and to make as many pictures of objects as possible using the nine triangles. The results revealed that the Japanese students scored significantly higher than their American counterparts on all variables except flexibility of content, synthesis, and articulation in telling a story through pictures. The American students lacked other indicators of quality in creative thinking, such as humor, fantasy, movement, and boundary breaking. Torrance noted that Japanese students exhibited reflective responses, often giving elaborate answers, whereas the American subjects gave quick responses, often starting the tasks even before the examiner finished giving instructions.

The instrument called "Your Style of Learning and Thinking" (Torrance, Reynolds, Ball, \& Riegel, 1978) was used in a second study by Torrance and Sato (1979b) to compare styles of thinking between 2000 Japanese and 2000 American students (college and high school). This test consisted of a 36-item self-report, involving a multiple choice questionnaire which gives scores for left and right cerebral hemisphere functions and integrated functioning. Each item provided the respondents with three choices (first, a right hemisphere function of processing information; second, a left hemisphere function; and third, an integrated way of processing information). They found that the Americans used logic and intelligence, while the Japanese used intuition and creativity. Over twice as many Japanese students as American students had a preference for intuitive approaches for solving problems.

\section{The Play/Creativity Link}

A potentially powerful link between play and creativity has been proposed by a number of scholars of creativity (e. g., Kogan, 1983; Lieberman, 1965, 1977). However, studies of this link did not begin until recent years. Both Japanese and American researchers agreed that more study needs to be done in this area. 
A Japanese educator (Nakagawa, 1991) who had been researching in the areas of play and creativity stated that, in 17th-century Japan, children's lives revolved around their play, and older children introduced traditional games to the younger generations. Children also created new games and rules within their groups. Their education was based on constant mutual contact with peers (Nakagawa, 1991). In her words, "...their process and play inspired creativity, provided a treasure house of knowledge, and gave them the skills to live" (p. 12). She further continued:

...today's children are surrounded by a network of adult management. Under such a network...freedom is quite restricted. Where there is no freedom, creativity withers. It is now necessary to restore to children a world of free play and creativity. (p. 12)

Iverson (1982) described the link between play and creativity in the following manner: A playful outlook is a salient part of the creative stages (preparation, incubation, elimination, and verification). In Iverson's words, The ability to take a playful outlook is an important part of creative thought but too many of today's classrooms discourage playfulness--and thus squelch creativity" (p. 693).

Vandenberg (1980) claimed that we could benefit from further research on the relationship between playfulness and creativity because an analysis of the relationship between a playful personality trait and its behavioral manifestation can contribute to the meaning of playfulness at various developmental points. In Vandenberg's words, "...the answer to the question of whether more playful individuals are more creative is a tentative maybe. Research to data has served mainly as a preliminary step toward answering the question" (sic) (p. 62).

\section{The Relationship Between Playfulness and Creativity}

Playfulness is a psychological trait determined by individual differences in the disposition or attitude toward one's activities. Some researchers have studied playfulness as a personality trait (Singer \& Rummo, 1973: Singer, Singer, \& Sherrod, 1980). For example, Singer and Rummo (1973) measured the relationship between creativity and behavioral styles of 79 middle-class kindergarten children aged 52 to 77 months. The assessment of ideational creativity was derived from the work of Wallace and 
Kogan (1965) and Ward (1968) and assessment of behavioral styles was based on teacher ratings. They found that highly creative children tended to be meandering toward their work, more graceful, and more prone to respond to frustration aggressively. However, they found that creative boys were open, curious, playful, and expressive, but this was not the case in creative girls. Girls who were regarded as high in both creativity and intelligence as well as those regarded as low in both creativity and intelligence were found to be less open, less expressive, less self-confident, and less expressive in peer interactions. Thus, the results of their study revealed that there is a relationship between playfulness and creativity in preschool boys; however, their findings also indicated that the components of playfulness were differentially linked to gender.

In another study of playfulness and creativity, Singer, Singer, and Sherrod (1980) observed free play behavior of 87 3-and 4-year-old children from middle-class homes. They also measured the children's intelligence using the Peabody Picture Vocabulary Test and collected parental reports of a number of imaginary companions and of TV viewing behavior of children. Singer et al. found that the general playfulness of the preschoolers' activities could be characterized as a number of behaviors including imagination, language, social interaction, positive affect, mood, and activity levels. They also found that observed imaginative play did not seem to be highly related to TV viewing or to inner creative tendencies. Instead, the imaginative play of children seemed to be associated with the more general pattern of good-humored playfulness and social interaction.

Playfulness in young children was defined by Lieberman (1965) as physical, social, and cognitive spontaneity, manifest joy, and sense of humor. She found that playfulness and divergent thinking were correlated in her sample of 93 kindergarten children (mean ages 5 years, 6 months) from middle-class families. The instruments of this study were the teacher rating scale of playfulness developed by Lieberman (1965), a test for divergent thinking adapted from Torrance and Guilford, and the Peabody Picture Vocabulary Test. Her findings indicated a linking of personalty traits to divergent thinking. She also found that joyful spontaneity in play helped the child in working with a complex task. She 
concluded that both playfulness and divergent thinking indicated freedom, spontaneity, and joy. However, because the subjects of her study were only middle-class American children and Lieberman did not provide information on the types of programs in kindergarten (e. g., academic-oriented, playoriented), the generalization of the use of this instrument to children having different backgrounds may not be suitable.

Following Lieberman's lead, Barnett (1990) also defined playfulness as physical, social, and cognitive spontaneity, manifest joy, and sense of humor. She claimed that because playfulness is a characteristic of the child, in order to understand play, it is better to focus our attention on playfulness as an internal predisposition to be playful. She studied 388 children of normal intelligence aged from 29 to 61.5 months from middle-class families using her scale which was a revised version of Lieberman's playfulness scale from 1965. Teachers twice rated their children's playfulness using the scale developed by Barnett. Her study focused on identifying and measuring playfulness. She found her scale to be reliable, valid, and efficient in measuring the child's playful interaction with the environment.

Although Barnett included Asian-American, African-American, and Caucasian children in her study, they were all middle-class children in day care centers. Children attending day care centers experience different programs from those attending preschools and kindergartens. In addition, her scale focused only on the overt behavior of children; inner thoughts and motives were not measured.

Barnett and Kleiber (1982) found that playfulness of preschool and kindergarten girls was related to divergent thinking. The subjects of this study were 106 preschool and kindergarten children aged from 3.89 to 6.03 years. Three instruments (The Peabody Picture Vocabulary Test; The Playfulness Scale by Lieberman, 1965; A Measure of Divergent Thinking by Torrance, 1960) were used in this study. The results of the study showed that children's playfulness is a trait which needs to be measured with respect to sex differences because children's early play and socialization experiences are different and parental and teacher expectations of boys and girls also are different. 
Barnett and Fiscella (1985) studied the playfulness and creativity of gifted and nongifted preschool children from middle-class homes. Fifteen gifted children and 20 nongifted children were identified by using the Stanford-Binet Preschool Intelligence Test. The children were observed and rated on the degree of playfulness, using the Lieberman Scale (1965). Barnett and Fiscella found that the gifted children were more developmentally advanced in certain play styles. These play styles were of a wider variety, possessing higher levels of imagination and creative playful interactions with the incorporation of new objects into the play. In addition, both gifted boys and girls exhibited more physicality in their play activities than girls of average intelligence. The gifted children tended to be more creative and imaginative in their play and to enjoy joking and teasing with other children. It should be noted that no mention was made regarding boys of average intelligence in the comparison of the physical play of gifted and nongifted children.

\section{Playfulness}

According to Erikson (1972), it is important to study playfulness because playfulness is an attitude, is the quality of being alive, and is important in life. He also believed that childhood playfulness must be renewed at each level of our development in order for us to become complete adults. Playfulness can determine one's attitude toward approaching life. Tasks or environments ordinarily seen as mundane or difficult can be approached with a playful attitude that can make them enjoyable.

Erikson (1977) stated that when children are mastering some traumatic experience through play, playfulness is the key factor that transforms the play event into an act of renewal. The play acts as communication and confession, and playfulness acts as joyful self-expression.

Similar to Erikson, Millard (1974) regarded play as being the attitude and the mood of the person rather than what he or she is doing. Play can be playful or non-playful depending upon the player's attitude. For example, a child who is trying to build a bridge with blocks can be either playful or non-playful. When he or she builds with laughter, pleasure, and enjoyment, the child is playful; 
however, when the child is seriously involved with blocks, he or she is not necessarily being playful. A playful attitude can turn work into play. Millard further explained that instead of describing play as a particular activity, we need to describe it in terms of the attitudes and conditions under which it is performed.

Levin (1967) also postulated that playfulness is important because a person with playful and humorous attitudes will not take himself or herself seriously. While children playing intensely may be seen as serious, laughter and fun always accompany their play. In Levin's words, "Humor is important to the full enjoyment of any sport. By assuming a playful, humorous attitude, we are not taking ourselves or our performance too seriously" (p. 61).

Measuring playfulness. Measuring playfulness as a disposition has been done by few researchers (Barnett, 1990; Lieberman, 1965; Rogers, 1988; Tegano, 1990). Barnett (1990) and Lieberman (1965) developed their own scales based on the definition of playfulness as social, physical, and cognitive spontaneity, manifest joy, and sense of humor. Moore (1985), Rogers (1988), and Tegano (1990) assessed playfulness, using as a definition the six dispositions of play described by Rubin et al. in 1983.

Rogers (1988) found that playfulness can be reliably measured and seems to be distinct from external dependency. Based on the six dispositions of play defined by Rubin, Fein, and Vandenberg (1983) (intrinsic motivation, process orientation, organism domination, nonliterality, freedom from externally imposed rules, and active involvement), Moore (1985) and Rogers developed the instrument called the Child Behaviors Inventory to measure children's playfulness. After factor analysis of the data, Rogers found that one factor represents playfulness and the other factor (externality) contributes to nonplay. 


\section{Summary of Review of Literature}

In sum, artistic creativity refers to one's abilities that make aesthetic awareness of the world possible. Feeling, thought, and belief can be expressed through art. Children learn to express themselves and their ideas through drawing and thus can develop aesthetic skills.

Creativity has been measured by a variety of methods (e. g., using drawing or art products, twoand three-dimensional materials, visual stimulus materials, etc.). Some researchers found the use of professional artist's ratings to measure children's art products to be reliable and valid.

Both Japanese and American educators agreed that more study needs to be done in the area of play and creativity. Some have claimed that play inspires children's creativity and others have reported that playfulness promotes creativity. In search of the relationship between playfulness and creativity, some studies found such a relationship in young children. Measurement of playfulness as a disposition has been done by only a few researchers but the few existing scales that assess playfulness seem to be reliable and valid. However, no research has studied the relationship between playfulness and artistic creativity of Japanese preschool children. Therefore, this study was undertaken to fill this gap in our knowledge of such a relationship.

\section{Japanese Educational Context}

Japan is a relatively homogeneous society; thus, in Japan there is little variety racially and economically. Of Japanese people, $96 \%$ consider themselves middle-class (White, 1984). Given factors such as these, one can assume that there is a consensus of values in Japan regarding tradition, ideology, and education (Shigaki, 1983; White, 1984).

In their cross-cultural study of both Japanese and American preschools, Bacon and Ichikawa (1988) found that: The Japanese kindergartens are much less structured and more play-oriented than are American kindergartens...The Japanese children spent more than twice as much time in free play as the American children...."(p. 381) 
It is important to note that many Japanese preschools subscribe to group orientation programs. Tobin et al. (1989a) described Japanese group orientation in this way, "...groupism is the key distinguishing factor between Japanese and American preschools, and indeed, between the two societies" (p. 39). The main functions of the preschool are to introduce the child to a group life and for the child to learn to play together with other children in a group environment.

Preschool education has become a major focus for Japan as the number of children attending preschool increases each year (Tobin et al., 1989a). Tobin et al. (1989a) described this phenomenon in the following way:

In Japan the increasing nuclearization and gentrification of the family brought on by a shrinking birthrate, an ongoing migration of young people from extended households in the country to single-family apartments in large cities, and the rise of the middleclass...have led Japanese parents to believe that preschools offer their children their best chance of learning to function in a large group and of becoming in Japanese terms, truly human. (p. 2-3)

Many Japanese children begin early childhood education at age 3 years and continue till age 6. Approximately $60 \%$ of preschools can be claimed as private, $40 \%$ as public, and less than $1 \%$ as national (Tokyo Statistics Bureau, Prime Minister's Office, 1982). The Ministry of Education provides both private and public preschools with national aid for building and purchasing equipment and a modest yearly subsidy per student (Tobin et al., 1989a).

According to Tobin et al. (1989a), the Japanese traditional preschools value Western notions of child development because they were established by American missionaries, Christians, and Japanese educated in the West. Tobin et al. explained that "...all Japanese preschools from the most free to the most traditional mix Western and Japanese values and approaches" (p. 53). Lewis (1984) and White (1987) reported that the traditional Japanese preschool provides a relaxed, play-oriented, nonacademic program in the context of group orientation. 
Because the teacher-child ratio is one to $30-40$ children, the traditional Japanese preschool program promotes group orientation and cooperation. The individual does not stand out in the classroom and whole-group activity is emphasized. Therefore, all children in a class follow the teacher's direction simultaneously and teachers initiate special projects, lunch, and children's informal play (Lewis, 1984). It should be noted that a big class size and a high ratio of students to teachers have an important purpose in Japanese preschool education and Tobin et al. (1989a) described it in this way:

...to Japanese teachers and administrators group size is even more important because they believe that a large class better reflects the complexity of the outer world and gives each child a chance of getting to know and to deal with a wide variety of other children in a wide variety of situations. (p. 38)

By deliberately placing a large number of children in a classroom, Japanese educators aim to provide an environment which fosters the following educational goals in children: to minimize the impression of the teacher being in control, to delegate authority to the children, thus providing them with opportunities to develop a "good" child identity, and to avoid the attribution that children intentionally misbehave (Lewis, 1984).

One mode of learning which is professed by some Japanese educators (e. g., Ogawa, 1972; Tatsumi, 1990; Wada, 1932) is play. Tatsumi (1990), one of the more renowned educational psychologists in Japan, believed that play facilitates learning in children and that playful children become creative and artistic adults only when they have a chance to play as much as they want in childhood. Wada (1932), one of the leading pioneers of Japanese early childhood education, stated that through play children learn about the world and that play facilitates holistic human development.

In contrast to the playful context found in early childhood programs, once formal schooling begins at age 7, the opportunity for play diminishes drastically and this has been a cause for concern among some Japanese leaders. For example, Nakagawa (1991) stated that because of strong adult management in Japan, today's children seem to lose their freedom and under such a network of adult 
management, children's creativity diminishes. In Nakagawa's words, "Where there is no freedom, creativity withers. It is now necessary to restore children to a world of free play and creativity" (p. 12).

The above statements by Tatsumi and Nakagawa seem to be contradictory, but according to Torrance (1980), although the Japanese have rules for just about everything, under the structure and limitations of these rules, they are free to diverge, invent, and change. At the 1983 Conference on Child Development in Japan, Lewis (1986a) found a similar discrepancy of views of Japanese education. Some conference members described Japanese education as emphasizing rote memorization with little deviation from assigned tasks, while others saw Japanese education as child-centered in which the child takes the initiative in learning. One conference member stated, "It's as if we're talking about two different countries" (p. 197). Interestingly, both Japanese and Americans held both points of view.

I agree with the explanation by Lewis (1986a) regarding this discrepancy in Japanese education in which she stated that the discrepancy is related to the age of children being considered. Children under the age of 6 are encouraged to learn to work together cooperatively through play whereas older children receive more performance-oriented education, especially those who attend afterschool classes and are expected to achieve high scores and perform well on examinations. According to my observations of Japanese preschools and my conversations with Japanese early childhood educators, children in preschools are encouraged to develop social skills and learn to be members of a group, focusing less on the development of academic skills. Therefore, when we discuss Japanese education, it is important that a clear distinction between preschoolers and older children be made.

\section{Educational Goals and Functions of Japanese Preschool}

In order to understand Japanese preschool education, a review of Japanese educational goals, the educational context, and the overall views of Japanese preschools will be discussed here. Japanese preschools are called kindergartens and include the equivalent of the kindergarten year in the United States. 
The Japanese Ministry of Education, Science, and Culture (1981) declared the following to be the aims of preschool education:

1. to cultivate everyday habits necessary for a sound, safe and happy life and to effect harmonious development of bodily functions;

2. to make children experience in the kindergarten a group-life and to cultivate willingness to take a part in it as well as the germ of the spirit of cooperation and selfreliance (sic);

3. to cultivate the germ of right understanding of and the right attitude towards the surrounding social life and aspects;

4. to guide children in the right usage of the language and foster interest in fairy tales, and picture books;

5. to cultivate interest in creative expressions of children's own through music, play, drawing and other means. (p. 9)

The standard for kindergarten curriculum states its purpose as "...to have well-balanced teaching plans with activities appropriately designed by taking into account the difference in age among children, the length of the teaching period, as well as local conditions" (Shoji, 1983, p. 56). The following six subjects are taught in kindergarten: health, social studies, nature, language, music/rhythm, and drawing and handcrafts. In addition, athletic meets, picnics and field trips, several ceremonies and festivals (kindergarten founder's day, star festival, children's day, moon viewing, and doll festival) are also included in the school curriculum (Shoji, 1983).

The primary goal of Japanese preschool education is to develop a happy, engaged, and secure child who is able to work diligently and cooperatively with others (White, 1984). Kindergarten and elementary school teachers consciously teach group identity and school provides an opportunity for children to develop peer solidarity and peer cooperation (Singleton, 1989). Hendry (1986a) also stated 
that Japanese generally consider that preschools should be the place for their children to experience 'group-life' and to learn to play happily with other children.

According to their study (Tobin, Wu, \& Davidson, 1989a), the Japanese preschools help children develop the ability to balance between individualism and groupism. Tobin et al. stated that the tasks of the Japanese preschools are, "...to help children find this balance, to help them integrate the individual and group dimensions of self, to teach them how to move comfortably back and forth between the worlds of home and school, family and society" (1989a, p. 71).

Shigaki (1983) found that Japanese preschool teachers emphasize instilling in children those qualities relating to moral values (sympathy or empathy, gentleness, social consciousness, kindness, etc.). These teachers also reported that they hope to foster harmonious human relationships in children. In other words, they hope to foster a ningen rashii kodomo (human-like child). A ningen rashii kodomo is able to maintain harmony in human relationships.

In addition, developing a kodomo rashii kodomo (child-like child) is highly valued among Japanese preschool teachers (Tobin et al., 1989a). This notion of the child-like child includes empathy, gentleness, social consciousness, kindness, and cooperation. According to Tobin et al. (1989a), their interviews with Japanese teachers corroborated Shigaki's (1983) and White and LeVine's (1986) findings of the Japanese goals of preschool education; however, they found some additions to these highly valued traditional Japanese preschool education goals: They are independence, individuality, and creativity. Most preschool administrators and teachers attempt to balance both traditionalism and Westernism so that they can offer children the values of group harmony, interpersonal sensitivity, as well as creativity, independence, and self-confidence.

It should be noted that even though Japanese strongly emphasize group-orientation in the classroom, individual achievement is not discouraged as teachers and children know well the talents and abilities of each member of their own group (Hendry, 1986a). In Hendry's words, "It is part of the role of the kindergarten to develop creativity, self-reliance and self-awareness in their charges, and the 
teachers are in regular communication with the parents about each child's progress" (p. 56). She further continued, "Individuality is important, but it must develop within the limits imposed by being a member of a group" (p. 56).

\section{Academic Comparability of Japanese and American Students}

A number of studies have reported that Japanese students in both high school and elementary school outperform their American counterparts on tests in mathematics and science (e. g., Husen, 1967; Stevenson, Stigler, Lee, Kitamura, \& Hsu, 1985). Some studies (Bacon \& Ichikawa 1988; Stevenson, Stigler, Lee, Kitamura, Kimura, \& Kato 1986; Stigler \& Stevenson, 1991) focused on the excellent academic performance of Japanese preschool and elementary school children. Stevenson et al. (1986) found some differences in mathematical achievement between Japanese and American first- and fifthgraders. They claimed that Japanese children do better on tests of mathematics because they spend more time in school and devote more time to homework than do their American counterparts.

In addition, in their study of Chinese, Japanese, and American elementary school children, Stigler and Stevenson (1991) described the Japanese elementary classroom as a thoughtful, relaxed, and nonauthoritarian environment. Japanese teachers often rely on students as a sources of information, activities are focused on problem solving, and there are frequent verbal interactions between the teacher and students rather than the reliance only on the teacher's lecturing. In their words:

...whole class instruction in Japan and China is a very lively, engaging enterprise. Asian teachers do not spend large amounts of time lecturing. They present interesting problems; they pose provocative questions; they probe and guide. The students work hard, generating multiple approaches to a solution, explaining the rationale behind their methods, and making good use of wrong answers. (Stigler \& Stevenson, p. 18) In their study of Japanese and American kindergartners, Bacon and Ichikawa (1988) found that although Japanese mothers seem to be less demanding about their children's academic performance than American mothers, Japanese children outperform American children on tests of mathematics. They 
found that "The Japanese children spent more than twice as much time in free play as the American children, while direct teaching consumed nearly 4 times as much classroom time in the U.S. as in Japan" (p. 381). Bacon and Ichikawa also found that the Japanese preschoolers spent much more time smiling, touching, and talking to each other than their American counterparts.

In comments that support Bacon and Ichikawa's findings, Tobin et al. (1989a) stated in their cross-cultural study of Japan, China, and the U.S. that "In general, academic instruction is stressed more in China, play is stressed in Japan, and the picture is mixed in the U.S." (p. 195). Because of the educational pressures in primary and high schools, Japanese parents and teachers view play and fun as appropriate and crucial functions of the preschools.

\section{Overall Views of Japanese Preschools}

There are strict regulations for teaching in Japanese preschools (Tobin et al., 1989a). It is required that Japanese preschool teachers have 2 or 4 years of college education (The Minister of Education, Science, and Culture, 1981).

Japanese children attend school 240 days a year (White, 1984) and the teacher-student ratio in Japan is 1:40 for nursery schools and 1:50 for elementary and secondary schools (Cummings, 1980; Lewis, 1984). In spite of larger classes, Japanese teachers spend only $10 \%$ of class time organizing, controlling, and disciplining the class (White, 1984). Imamura (1986) explained that the reason for this smaller amount of control being needed in the classroom is because Japanese children are taught to respect authority at home before they enter school.

Japanese preschool education reflects both Eastern and Western values. Nagano (1984) claimed that when we study Japanese education, we should not ignore historical background. Historically, Japanese believe that any child can be educated to become successful and to become a better person. Because of this belief rooted in Japanese culture, and because the Japanese have also adapted the Western belief that children should grow up naturally, early childhood education in Japan oscillates 
between this traditional belief of personal improvement through education and the Western belief that children should grow up naturally (Tobin et al., 1989a).

Lewis (1986a) indicated that her notions of Japanese preschools being regimented were based on the written descriptions by others. However, she found that "The noise and chaos level of Japanese nursery schools was perhaps the single most astonishing aspect of my observations. Very high levels of spontaneous background noise (shouting, laughing, and so forth...)" (p. 196). She further explained, "It was dramatically demonstrated that identical uniforms and formal daily ceremonies imply nothing about the level of spontaneous play or the degree of discipline" (p. 196). One possible reason for the Japanese children's noise level being so high is that Japanese adults value children's vigor and that considerable classroom noise does not reflect negatively on the teacher (Lewis, 1986a). Tobin et al. (1989b) supported Lewis's findings regarding the noise level and chaos of Japanese preschools. Tobin et al. (1989b) found that many Japanese preschool teachers and parents of preschoolers believe that it is important that teachers should not be like mothers nor the school like the home. Therefore, a key distinction between the world of home and school is the level of noise and chaos. Tobin et al. called this developmentally appropriate chaos because Japanese teachers believe that periods of chaos can provide a healthy environment for young children. Thus the preschool provides a place for children to be real children, and it follows that they should be noisy and lively. "Lively and boisterous activity is encouraged..." (Simmons, 1990, p. 60). This concept of children being noisy comes from the traditional belief that children should be lively, active, and brisk, thus indicating that the child is healthy and childlike.

Both Lanham (1966) and Shigaki (1983) observed an uninterrupted attention span of long duration among Japanese preschoolers. Shigaki (1983) explained some reasons for the long attention span of Japanese children in the following way: Japanese teachers choose play materials according to the children's capabilities and for their satisfaction. Moreover, children are encouraged to maintain their attention during large blocks of time. In Shigaki's words, "The daily schedule was such that changes of 
activities were paced more leisurely and children appeared to be engaged in the same activity longer than their American counterparts" (p. 22). In addition, Japanese preschoolers spent more time in transition from one activity to another than American preschoolers (Bacon \& Ichikawa, 1988).

A number of researchers (Duke, 1986; Hendry, 1986a; Simmons, 1990; Singleton, 1989; White \& LeVine, 1986) referred to a Japanese cultural theory of learning as ganbare (persistence). Ganbare is interpreted as, "Don't give up, endure!". Duke stated that "Throughout the lifetime of the Japanese they are surrounded, encouraged, and motivated by the spirit of ganbare. It begins at home. The school takes it up from the first day the child enters the classroom" (1986, p. 122). Ganbare has the same meaning to all Japanese: Whatever you do, do your best and don't give up.

One of the teacher's responsibilities is to instill the spirit of ganbare into the students (Duke, 1986). In Duke's words, "Whenever there is a task to perform, an activity to participate in, a test to prepare for, the child is encouraged by the teacher to ganbaren (p. 127). The spirit of ganbare strongly pervades the modern Japanese world as a fundamental feature of being Japanese (Duke, 1986). Singleton (1989) referred to ganbare in this way, "...it is used among members of a group to encourage each other in cooperative activities" (p. 10).

The predominant research on Japanese education shows inconsistencies in the researchers' views of Japanese school systems. For instance, the following researchers praised Japanese education: Cummings (1980), Lewis (1984, 1986a), Torrance (1980, 1982), Vogel (1979), and White (1984). As proof of excellence, they pointed out such features as the use of groups in the classroom, the enforcement of egalitarian education, and the implementation of cooperation. Torrance $(1980,1982)$, who observed many preschools in Japan, stated that the preschool children's physical skills, music performances, art products, dramatic enactments, and group-cooperation skills were beyond what he thought would be possible for these ages (3- to 6-year-olds). In discussing Japanese creativity, Torrance noted: 
...when the members of a group cooperate with one another, creativity is probably at its highest...I saw a group of 4-year-olds working to set up one room for the next session. The teacher was there but she did not interfere or give suggestions. The children stumbled but came through in great shape. In the USA, peer pressure is a very powerful inhibitor of creativity. It is less inhibiting in Japan because it is groupcentered (not teacher-centered). They are excelling for the group and are, therefore, protected from this peer pressure. (E. P. Torrance, personal communication, November 7, 1986)

Torrance had further praise regarding the quality of the teamwork, the problem solving, and the creativity of Japanese children's groups in the classroom. For example, through group projects, group trips, and class organization, students are taught the skills of group learning and of being sensitive to their peers.

Cummimgs (1980) and Lewis (1984, 1986a,), Vogel (1979), and White (1984) also lauded the use of groups in the classroom by the Japanese. They claimed that through egalitarian education, Japanese education aims to develop a happy, cooperative, and hard-working child who is capable of working with others in group situations. In this respect, the children are taught friendship, cooperation, cordiality, and discipline.

Similarly, Lewis (1984, 1986a, 1986b) noted that in preschool situations, children are encouraged to solve their problems without the teacher's intervention. As an example, teachers deliberately provide fewer art materials so the children will encounter a problem of sharing they will need to solve.

Other researchers, (Azuma, 1986; Cummings, 1980; Imamura, 1986; Inagaki, 1986; Vogel, 1979), however, view the Japanese educational systems as lacking in the development of creativity, and recently, government officials in Japan have identified this as a critical problem (Marshall, 1986). Cummings (1980) and Vogel (1979), who praised the Japanese educational system for the use of groups, found many problems as well, including a lack of creativity. Regarding this issue, they pointed out that it is 
difficult for a person in Japan to deviate from the group. The deviant individual experiences isolation and ridicule from his or her peers and is criticized and forced to follow the group's guidance. Vogel (1979) noted that this isolation and criticism smothers individual rights, individuality, and creativity. He further pointed out that during the years of Japanese compulsory education, there is almost no flexibility in the curriculum that could otherwise encourage the development of creative imagination. Additionally, Vogel (1979) found that the Japanese excel in research involving cooperation but they lag behind in research relying on individual creativity. Two Japanese researchers (Azuma, 1986; Inagaki, 1986) supported Cummings and Vogel's statements. As insiders, Azuma and Inagaki recognized a strong tendency toward formalization in Japanese education. Inagaki defined this formalization as being institutional, subject-matter centered, or teacher-centered.

\section{Creativity in Japan}

It is important to note that the Japanese concept of creativity may differ from that of the American concept (Lewis, 1986b). In Lewis's words:

Several sources of evidence suggest that Japan and the U.S. may differ on the cultural value placed upon creativity...creativity in the Japanese arts achieved through repetition and mastery of prescribed forms. Deviation from the prescribed forms is a mistake, not creativity, unless one has already achieved mastery by devoting to the art the many years necessary to attain the status of expert. (p. 42-43)

In addition, Lewis (1986b) pointed out another difference in creativity between the U.S. and Japan. She explained that the two nations have different perceptions regarding the value of originality: ...the predictors of school achievement in the U.S. and Japan reveals that originality at age 4 predicts school achievement at age 11-12 in the U.S. but not in Japan. In contrast, persistence at age 4 predicts later school achievement in Japan but not in the U.S. These findings suggest that originality in the U.S., and persistence in Japan, enable children to succeed in their respective educational systems. (p. 43) 
To recapitulate, Japanese preschool education places a high value on children's play and creativity and aims to develop a sound, happy child who can work with others harmoniously. However, existing research on Japanese education reveals inconsistencies in the researchers' views of Japanese education systems. Some have praised Japanese education for the use of groups in the classroom, the enforcement of egalitarian education, and the implementation of cooperation. On the other hand, others have viewed Japanese education systems as lacking in the development of creativity because it is difficult for a person to deviate from the group, and the pressure to conform to a group norm smothers one's creativity. It is important to note that creativity may be viewed differently in Japan relative to the United States because of cultural differences.

Studying Japanese preschool education adds a useful and insightful understanding of a different culture to the educational field. Because European and American studies have dominated behavioral sciences, investigating the less-explored but potentially rich field of Japanese education can promote and foster a new outlook in education.

As the number of children attending preschools increases each year, preschool education has begun to be studied by educators and psychologists. However, no studies of the relationship between playfulness and creativity in Japanese preschool children have actually been done. Therefore, this study was undertaken to explore and describe Japanese preschoolers' playfulness and creativity. 


\section{Chapter 2}

\section{Methodologies}

\section{Methods}

The purpose of this study was to describe and to explore the relationship between playfulness and creativity among a sample of Japanese children. This chapter includes information about informant recruitment, instruments, data collection procedures, and areas of research interest which guided observations and interviews. Permission to work with the children and teachers was given by the director of school, and the children's parents were informed of this research by him.

Both quantitative and qualitative methodologies were used in order to obtain rich data. Quantitative methodologies were used to assess playfulness and creativity. Qualitative methods were used to gain descriptions of individuals and detailed, sensitive information. According to Berg (1989), the triangulation of data from a variety of methodologies provides a substantive picture of reality. Marshall and Crossman (1989) also postulated that the use of triangulation can strengthen a study's usefulness in other settings.

\section{Identification of School and Informants}

At the end of December, 1991, I contacted the director of a private kindergarten in Kawasaki City and asked his permission to work with the children and teachers. The permission was immediately granted and I sent a letter to explain what I would like to do at his school. I have been doing research at this school since 1986, and the director, assistant director, and I have remained friends.

I gained entry to my research settings in Japan quickly because of my indigenous status. Berg (1989) stated that in some cases, a researcher's indigenous status helps him or her gain entry into a research environment more quickly. As a Japanese person, I possessed certain strategic advantages and I was also able to blend into the settings. However, I was aware of the fact that my perspective oscillated between that of a Westerner and that of an Easterner during my research. In other words, 
while I was in the Japanese settings, I was accepted as a member of the group, but when I analyzed the data, my thinking was that of a Westerner.

I collected data from various sources including 5- and 6-year-old children, their teachers, and the administrator of this kindergarten. Twelve children were selected for more in-depth study and observation. To identify children who were seen as high and low on a measure of playfulness, the six teachers were asked to rate the playfulness of all 164 children in six classrooms using the Child Behaviors Inventory (Rogers, 1988). Three children scoring highest and three children scoring lowest on the CBI were chosen from each of the six classrooms, yielding a total of 36 children. Then, in order to represent both genders equally, I selected from the 36 children three highest scoring boys as well as three lowest scoring boys, and three highest scoring girls as well as three lowest scoring girls, totaling 12 (six boys and six girls).

\section{Methods of Gathering Data}

\section{Playfulness}

Playfulness of all 164 children in the classrooms of 5- and 6-year-olds was rated by their teachers, using the Child Behaviors Inventory (CBI). The CBI is a 31-item questionnaire designed to assess playfulness in children (Rogers, 1988). Items represent six dispositions of play described by Rubin et al. (1983). Items for the instrument were contributed by 16 scholars in the field of play and were evaluated by five other scholars. Factor analysis yielded two factors: playfulness and externality. Externality referred to the child's tendency to depend on other people for direction or to be affected by environmental factors. Cronbach alpha coefficients were high, ranging from .81 to .94 for playfulness and .62 to .72 for externality. Interrater reliability between teachers was $r=.60$ for playfulness but moderate for externality $(r=.42)$. The items were translated by the researcher into Japanese and three Japanese educational psychologists viewed the translation, concurring that it was accurate. The CBI is included in Appendix A (both in English and in Japanese). 


\section{Creativity}

Two measurements of creativity were collected from the 12 target children; one was The Test for Creative Thinking-Drawing Production (The TCT-DP) (Jellen \& Urban, 1986) and the other was derived by assessing the children's free drawings. The TCT-DP's interrater reliability yielded correlation coefficients between .88 and .97 . This test was chosen because the time it takes to administer and evaluate the test is minimal, the instructions are simple and can be applied to different ages, the administration and evaluation of the test requires little training, and the cost of the TCT-DP is relatively low. The TCT-DP consists of six figural fragments and is a paper and pencil test which provides several forms of figural fragments to which the child may respond freely and imaginatively. The instrument is shown in Figure 1.

\section{Scoring of The TCT-DP}

Jellen and Urban (1986) described the 11 key elements of the Test for Creative Thinking in the following way:

1. Completion $(\mathrm{Cm})$. One point for any continuation and extension of the six figures (6 points maximum).

2. Additions (Ad). One point for any additions or extension or continuation of figures such as points, lines, patterns, etc. (6 points maximum).

3. New elements $(\mathrm{Ne})$. One point for any figure, symbol, or element created in addition to but independent of the given figures (6 points maximum).

4. Connections made with a line (Cl). One point for any drawing connection made with a line between one figure and another ( 6 points maximum).

5. Connections made to produce a theme (Cth). One point for each theme-bound figure (any figure contributing to a compositional theme; 6 points maximum).

6. Boundary-breaking that is fragment-dependent (Bfd). Six points for any extension/continuation of the small open square located outside of the square figure. 


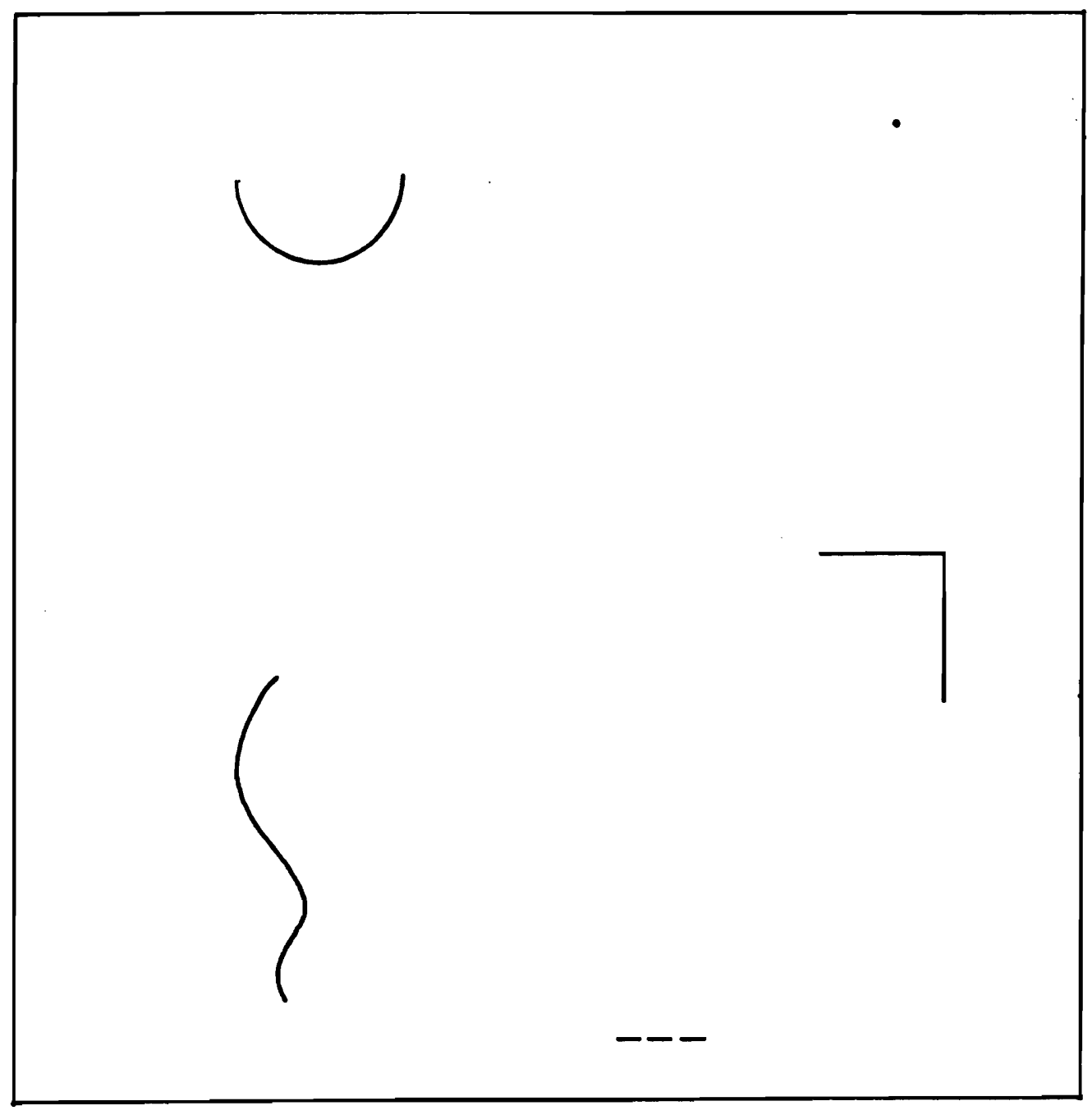

Figure 1. The Creativity Thinking-Drawing Production Test

41 
7. Boundary-breaking that is fragment-independent (Bfi). Six points for any drawing independent of the small open square that breaks the square frame.

8. Perspective $(\mathrm{Pe})$. One point for each figure that breaks away from two-dimensionality (6 points maximum).

9. Humor ( $\mathrm{Hu})$. Any drawing that indicates a humorous response (6 points maximum).

10. Unconventionality $(\mathrm{Uc})$. A. 3 points for any manipulation of the test (turning the test), B. 3 points for any surrealistic/abstract elements (the use of an abstract theme), and C. 3 points for any combination of figures, signs, and/or symbols (the semi-circle does not become a stereotypical sun or face; 12 points maximum).

The final scoring criteria used by Jellen and Urban (1986) was not used since this variable had an inhibitive impact on the children's creativity. For example, some children asked me if it was all right for them to draw more or told me that they were not finished with the drawings. The highest score possible for the TCT-DP is 66 points without including the score for speed. The score sheet is shown in Figure 2.

Two judges trained in child development, including this author, independently scored the test results. They were in agreement on 91 percent of the TCT-DP scores. Of the three tests administered to individual children, the highest score from each triad of TCT-DP drawing tests was used as the measure of each child's creativity.

In addition to the TCT-DP Test, I obtained the target children's two free drawings as another measurement of their creativity. Free drawings were assessed by a method described by Acharyulu and Yasodhara (1984) who measured the creative thinking abilities of preschoolers in India through their drawings. Preschoolers $(n=116)$ were asked to draw whatever pictures they wished within a time limit of 40 minutes. These researchers assessed each drawing using Torrance's (1966) method of scoring (fluency, flexibility, originality, and elaboration). The creativity measures derived from the drawings of preschoolers were validated against two artist raters and were satisfactorily significant, according to 

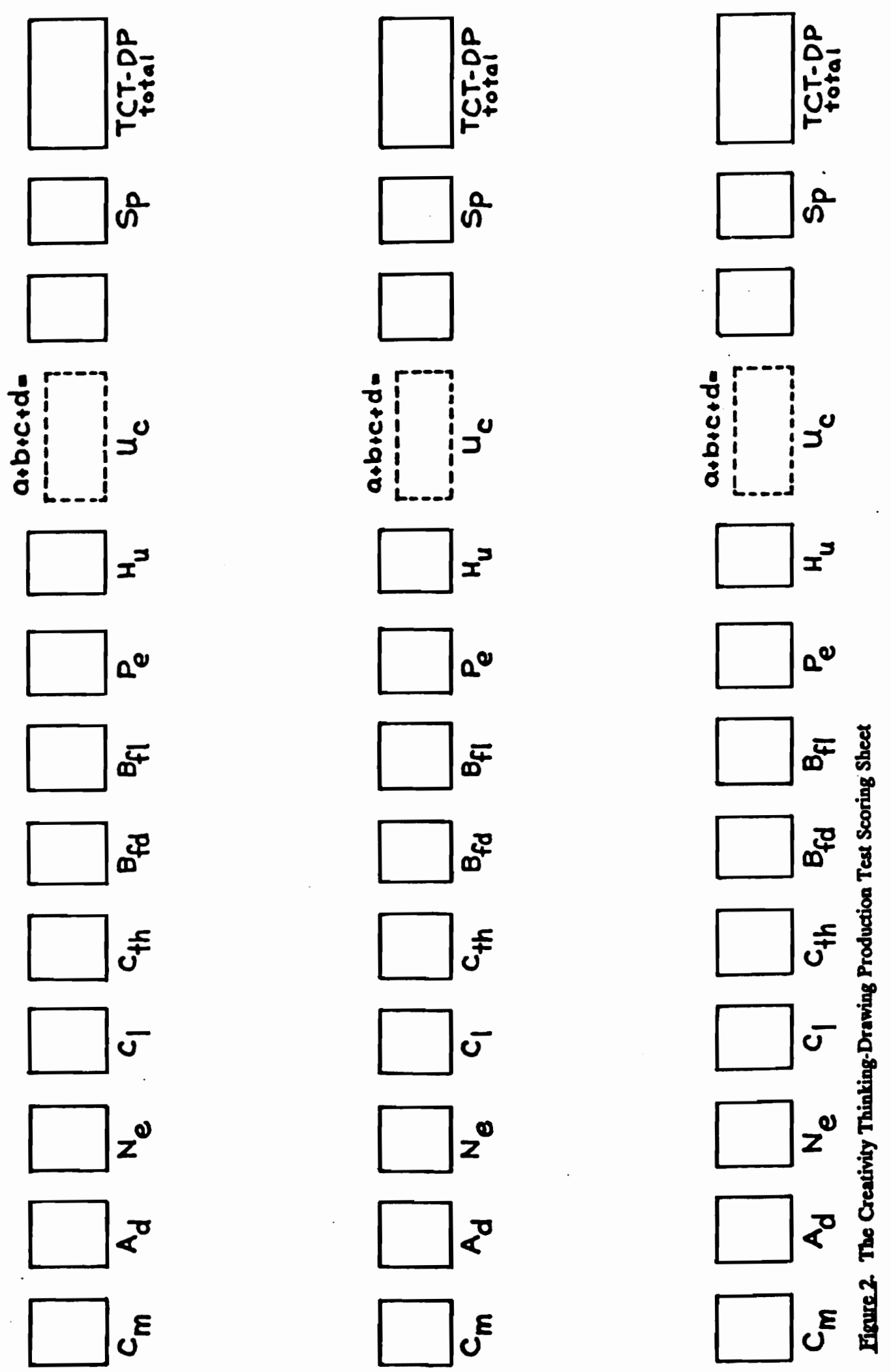
Acharyulu and Yasodhara (1984). Thus, they considered that the interscorer reliabilities for measures of fluency, flexibility, originality, and elaboration warrant the use of drawings in assessing preschoolers' creativity. However, in this case, the method of obtaining the drawings from the children was modified as I asked the teachers to collect the drawings the children had done during art activity where a time limit was not imposed on them.

\section{Scoring of the Drawing Test}

Acharyulu and Yasodhara (1984) described the following four types of scoring for the Drawing Test:

1. Fluency. The total number of pictures drawn indicates fluency (repetitions are excluded).

2. Flexibility. The number of different kinds or classes or categories of pictures drawn indicates flexibility.

3. Originality. Any picture drawn by more than 5 percent of the target children received zero originality, pictures drawn by $5,4,3,2$, and 1 percent of the children received originality weights of $1,2,3,4$, and 5 respectively.

4. Elaboration. The number of details drawn indicates elaboration. Each significant and meaningful detail received 1 point.

After I scored the drawings using the Drawing Test measurement described above, these drawings were passed on to two professional artists and they scored the drawings using the artist's creativity measures described by Acharyulu and Yasodhara (1984). Each artist was asked to independently rate the drawings on a 5-point scale using the following four criteria:

1. Number of meaningful drawings.

2. Number of different categories.

3. Unusual pictures and/or color representation.

4. Details furnished in meaningful drawings. 


\section{Data Collection Procedure}

\section{Playfulness}

The six teachers were asked to rate their students' behavior using the CBI (Rogers, 1988). They were not informed of the fact that this scale was for measuring playfulness because I did not want to bias their assessment of children. The six teachers completed the CBI one afternoon in the office.

I videotaped interviews of each teacher in one of the private rooms in the school asking about the target children's playfulness. My interview questions for teachers regarding playfulness are shown in Appendix B.

I conducted observations of each target child in the classroom for 20 minutes and videotaped the behavior of each individual. In addition, I spent a day in each classroom, observing, making notes, and videotaping the activities of each classroom.

\section{Creativity}

The TCT-DP was administered individually to the target children. Administration of the test took place in one session in a room isolated from the other children. The TCT-DP was given to each selected child three times in order to give them an ample opportunity to work with the material, and the process of completing the test was videotaped in order to observe the children's physical movements, facial expressions, and any reactions to the test. Then the children were asked to complete a drawing that someone else had begun.

I interviewed the target children during the TCT-DP Test, asking each child, "Tell me about your drawing while you are working on it." I also encouraged them to talk while they were drawing because I was interested in their thoughts. Additional questions that I asked during the test are included in Appendix C. The test was given by me.

The target children's free drawings were collected by their teachers during art activity time. Each teacher instructed the whole class to draw whatever they wanted and the teachers then selected the target children's drawings for me. In addition to administering the TCT-DP Test to the target 
children, I interviewed the six teachers to gain information about the target children's creativity. I also observed, took notes, and videotaped the target children's behavior in their classrooms.

Additionally, I collected two kinds of general information on the target children. The first source of information was gained as a result of the informal interview with the assistant director. I asked her about the target children's behavior in school and about their family situations. The second source came from the "Social, Emotional, and Physical Development List" containing 43 items which the teachers used to check their children's development. The List included questions regarding such traits as the tendency to play alone, the ability to enjoy books, the tendency to fight with others, the ability to use chopsticks well, and the capacity to listen to others. In order to gain more understanding of the target children, I also videotaped an interview with them about their favorite and least favorite things involving school, play, friends, and family. The interviews took place in the same private room immediately following administration of the TCT-DP test. The questions are shown in Appendix D.

Before the interviews, I informed both the children and teachers that all information given by them would remain confidential and that there would be no right or wrong answers. Interview questions for both teachers and children are included in Appendix C and D. In addition to the teachers' interviews, I obtained the teachers' written subsequent responses a week after the initial interviews in order to elaborate on their responses.

Participant observations were incorporated into this study to gather information about the target children. This observation method was used by Lewis (1984) when she observed Japanese preschool children. I spent two days in each classroom of 5- to 6-year-olds. During the first day, I videotaped the materials and equipment in the classroom, recorded the daily schedule and any incidents related to children's playfulness and creativity. One aim of the first day's observation was to accustom the children and teachers to my presence. On the second day, I conducted observations of the target children, noting and videotaping the locations and activities of the target children and their teachers in their classrooms. 


\section{Analysis of the Data}

The quantitative data analysis was conducted to test for differences in playfulness scores according to gender, classroom, age, and creativity. The strength between playfulness scores and artistic creativity scores was assessed by correlational analysis.

The qualitative data analysis for this study followed the five stages suggested by McCracken (1988). In the first stage, I read each statement with no concern for its relationship to other aspects of the text. In the second stage I read each statement again and again to be familiar with my transcript. In the third stage, I started to watch for patterns and themes to develop. In the fourth stage, among themes, patterns, similarities, and contradictions, I chose relevant material and discarded the material that was not useful. And finally, in the fifth stage, I brought together the themes from each interview and unified them under the umbrella of the culture being studied and related them back to the review of literature. 


\section{Informants}

\section{Children}

The child informants (six 5-year-old children and six 6-year-old children of both genders) that I studied and observed in detail had many individual characteristics that distinguished them from each other. Although at first glance these boys and girls looked similar because of their Japanese characteristics of hair color and facial features and because they wore smocks and school uniforms, their individuality became apparent to me quickly.

Jiro, aged five, appeared frail, pale and smaller than his peers. He wore an orange hat that denoted which classroom he was in and like all the children, he wore a beige school smock wrapped around his tiny shoulders. Although he had a history of congenital asthma, he possessed a healthy growth of straight hair and a cheerful disposition in spite of his health problems. His teeth were neatly aligned pearls. He excelled in exercise class, diligently following instructions, while other boys were preoccupied with goofing off. He persevered with his tasks although he needed more time to finish than his peers.

Yoshiko was a busy five-year-old girl with thin, short hair. She also wore a beige school smock that had obviously served well its purpose of preventing her clothing from catching the stains of many school related activities. She was a spirited conversationalist with a distinctly loud and shrill voice, having an incongruously grownup way of speaking, perhaps because she was being raised by her grandparents. Her brown eyes were always interested in anything around her. She talked and moved constantly at her desk, reminding me of a bouncing, happy ball. She was also direct in expressing her opinions. When two boys were fighting each other and one started crying, Yoshiko went to them asking what had happened. When the crying boy was talking to Yoshiko, the teacher intervened and both boys started crying. Yoshiko moved away from the conflict and came to me saying in a concerned manner that was wise beyond her years, "That was her fault, she didn't have to say anything to them. They were about to make up." 
Five-year-old Kazu wore the same standard school smock and dark navy blue school shorts. The white knee-high socks he wore were brilliant against his small tanned legs. His dark hair was combed straight down into bangs but there were a few unruly strands that seemed to have wills of their own. His olive cheeks and his lips were full and almost pouting. His nose was long and his big eyes were complimented by dark, long eyelashes. He was direct in expressing his opinions, and in the classroom, his naturally curious nature always alerted him to any novelty or change. Nothing escaped his attention. For example, when I entered his classroom for the first time, he was the first one to jump out of his chair. He ran over to me and asked, "Who are you? What are you doing here? What do you have in your hand? You want to see what I can do with clay?"

Yuki was a tall, chubby five-year-old boy who had outgrown his peers substantially. Underneath his school smock, he wore a red sweater and dark long pants. He had been blessed with an abundance of eyebrows and his pretty eyes almost had the appearance of having been outlined with black eyeliner. Thoughtful, his eyes appeared to be searching the air in front of him for images to draw. He appeared to be soft-spoken and gentle, but this deceptive appearance was betrayed when he was observed interacting with others.

Tamiko, a 5-year-old girl, was dressed in a white sweater, a dark school skirt of navy blue, and wore red knee-high socks with a Japanese cartoon character on both sides of her socks below the knees. She had a soprano voice and a smooth, cheeky face, and high above her bubble cheeks, her widely set eyes were complimentary to her small, rosy lips. She reminded me of a little Japanese doll come to life. Her thin, dark hair was tied in the middle at the top with a red ribbon and she had an infectious smile that seemed to be a permanent fixture on her face. She was verbal and her responses to my questions were highly descriptive. Her slow pace and long attention span resulted in precise and orderly accomplishments.

My first impression of 5-year-old Shu with his round face rimmed by large oval glasses was that of a thoughtful owl. Drafting instruments could be calibrated from the circular perfection found in his 
features. His complexion was an interplay of autumn colors, consisting of golds and flushed reds. The black bangs formed a perfect equator around the circumference of his head, dividing it into equal parts of black hair above and face below. Again the clothing was similar to the other boys' with the smock and short school pants. Here was a child who was relaxed, easygoing, and was able to concentrate on his tasks.

Ken was a tall, skinny, energetic, and bright eyed six-year-old boy. The cuffs and collar of his light blue shirt stuck out of a smock which seemed out of place because of his relative height and mature looks. His dark hair, though cut short, was still a thick enough forest to prevent the sunlight from reaching his scalp. He had eyes that seemed to magically disappear into thin air when he smiled. He had a magnetic personality which pulled other boys into his universe. Observing Ken's endless playful kicks and thrusts was reminiscent of viewing Kung Fu movies without the physical contact. His "martial arts" skills were interrupted only by activities that found him either on the floor or involved in interactions that did not involve karate chops but gravitated more toward wrestling. In his interview with me, he said, "T like to wrestle with my dad at home." My strong impression of Ken was that here was a child who gave new meaning to the phrase, "Let's get physical."

Toyo, wearing the dark school skirt and a white sweater under her smock, was a six-year-old girl, with long, silky, soft hair tied to each side of a centered part with two pink ribbons. She had apple cheeks and a dimple underneath her pouting lips. Her eyes were large, dark brown, and almond shaped, accented by long eyelashes. Her button nose reminded me of a baby's. Her understanding of the teacher's directions were quick compared to her peers, which gave her time to finish her tasks and then to go and help other children.

Hiro entered the room with the same clothing as the other children with the exception of his gray sweater. He was a cheerful, short six-year-old boy whose contagiuous smile displayed unevenly spaced teeth. His voice was bubbly with joy. He sat nicely in his chair, attentive to his assigned tasks, and was diligent. He was always observing others with a smile and had a kind disposition. Although 
he was quiet, when he engaged in conversation, he had a great sense of humor and was easily able to amuse himself.

Maiko, also wearing the same school clothing, was a tall, cheerful six-year-old girl with quite long hair, separated into two opposing ponytails. She had relatively big hands and long fingers and it was not apparent until she smiled that she had an inexplicably missing tooth. She appeared to be coy and was deceptively still and quiet in the presence of strangers, her true nature being quite the opposite. Transition between activities came easy for her as she could easily convert her attention to a new task. Saiko, a six-year-old girl, wore black tights beneath her school clothing. She had long curly hair, parted in the middle with two braided ponytails held neatly and firmly to the sides of her head by pink ribbons. Her physical demeanor was gangly. Her small eyes, long neck and matching tiny voice conjured up the image of a miniature "Olive Oyl". She appeared to be a little girl lost in a jungle of activities. Being an only child seemed to cause her to require more time to warm up to people, but in spite of her shyness, she was self-sufficient if needed attention was not immediately forthcoming.

Mimi, dressed in navy blue tights under the typical school clothing, was a quiet six-year-old girl who had a cherubic face topped off with long black straight hair in a ponytail encircled by stars that held it in place at its base. Her eyebrows were straight and almost met each other in a comical way. Her voice was soft and almost inaudible, and I had to strain my ears to hear it. She responded quite often with a nod in place of an answer. She held her pencil firmly with one of her small, pudgy hands, and she was a shy, but willing participant in any given activity. Her long attention span and capacity to work in great detail were quite noticeable.

My overall impression of these children was that of highly energized, cheerful and boisterous, yet cooperative participants in my research. I felt that I was warmly accepted as one of their own and they made attempts to communicate with me in English knowing that I was living in the United States. They asked very frank and open questions as to whether I was Japanese or American because they were confused by the fact that I was Japanese but living in the United States. They were curious about 
American children and asked many questions about them. I was bombarded with invitations to play, to eat lunch, to go home with them, to do more interviews and videotaping. Here was the epitome of Japanese hospitality and graciousness wrapped in small packages. Although the children were dressed fairly uniformly and looked similar, I was able to remember their names that were spelled out in Hiragana (phonetic Japanese alphabet) on the circular name tags worn on the right side of their chests.

\section{Teachers}

The six teachers I interviewed and observed had much in common with the exception of one teacher. Five out of these six teachers were in their early 20's, had relatively long hair, wore no make up and looked more like teenage girls, and all had cheerful dispositions. It was obvious who was the head teacher because she was more mature looking and others sought her lead. However, during the interviews with these teachers, I found that each teacher was individually different but all shared a passion and devotion for preschool education.

Maya was a 21-year-old teacher who started teaching a class of 5-year-olds last year. Her hair was long and black, curved inwardly at the bottom. She had the air of a teenager and appeared to have an abundance of energy. Her speech was quick and her face expressive, and she used body language occasionally to emphasize her words. She was dressed in a white sweatshirt and dark skirt. When she entered the classroom, she wore a bright smile and started playing the piano before she said anything to the children. "Is everybody sitting now?" asked Maya as her fingers still danced upon the keyboard. It was apparent that she really enjoyed her job and the children.

Yuko, a 22-year-old teacher of 5-year-olds, had a pretty complexion and dark, shiny hair at shoulder length with a soft permanent. She had a romantic expression on her face and smiled a lot when talking to children. Yuko appeared to be both serious and feminine because of the arrangement of her facial features. She had the type of face that was considered the typical Japanese beauty of 5 centuries ago. Yuko's facial type, the oval shape, the elevated straight eyebrows, almond shaped eyes, small curled lips, and finely sculpted nose can be seen in many paintings and prints of antiquity. Because 
of her high voice, it was sometimes indistinguishable from those of the children. Although Yuko was very patient and gentle with the children, she was firm in talking with them.

Kyoko, a teacher of 5-year-olds, was a slender and tall 22-year-old woman with long straight hair braided in the back. She wore a dark blue shirt and a matching skirt. Kyoko appeared to be serious but was playful with her charges. Her voice seemed to always spontaneously rise to a higher pitch when she was conversing with children and she was thoughtful and tender toward them.

Keiko, the head teacher, taught a class of 6-year-olds. She was a short and trim woman who, although she was in her forties, appeared to be much younger. She was dressed in a gray sweater with dark pants and had her dark curly hair done up in French braids. The left side of her face was punctuated by a dimple. She had been teaching kindergarten for 20 years with the exception of the few years she had taken off to rear her own children. Keiko seemed to have a huge capacity for accepting everyone and made all those around her comfortable because of her calm and relaxed nature. She had a high youthful voice and talked openly and freely to both children and adults. Even in circumstances of panic where a child may have cut a finger or some such situation, her calm demeanor always served her well. Her sense of humor was also always an asset in her teaching.

Haru, a tall round-faced young woman in her early 20's was the teacher of a class of 6-year-olds. Her hair was long and flowed to her shoulders. She wore a blue and white striped blouse, a blue sweater, and a dark skirt. She appeared reserved and quiet but not so in front of the children. She was gentle and soft spoken but gave clear instructions to her children.

Mariko was in her early 20 's and was a teacher of 6-year-olds. Her lustrous hair was divided into two ponytails that cascaded down the front of her shoulders into her lap. Her hair accentuated her round features and gave her a girlish appearance. Her skin was clean and smooth and her dark clothes contrasted well with her clear moonlit skin. Her slightly breathy, yet soothing voice caught children's attention effortlessly. Her smile was never found to be missing in her classroom. 
I could not help thinking how young these teachers were with the exception of the head teacher. Tobin et al. (1989a) explained the reason why Japanese preschool teachers tend to be younger women in the following way:

The employment curve for Japanese women across occupations is M-shaped--most work for six or seven years after high school or three or four after college before retiring either when they marry or soon after, when they have their first child. (p. 68)

Another thing that amazed me was the amount of work that these teachers were required to do at school, including not only teaching, but keeping the classroom clean, picking up some of the children who lived far away and returning them home in the school van, as well as walking the children who lived nearby to and from school. Although the work was divided among all the teachers, I never saw them sit still for 1 minute. I thought to myself, "With the amount of work they have to do, they have to be young."

All of these teachers were skilled in playing the piano and used music rather than spoken words to signal any transition time. For example, the teachers played a specific song for cleanup and the children would know which activity to perform. Thus, the transition time went smoothly and was nonthreatening. It was more of a musical game in which the children could sing and clean up simuitaneously. The cleaning activity seemed chaotic, but by the time the cleanup theme was finished, everything was sparkling and clean. All during my observations of the cleanup period, I never saw or heard complaints from any of the children.

I liked the way the teachers greeted everyone who came to the school. Their "Good mornings" and "Hellos" had the cheerful tones of bells. They were friendly, polite, and most of all, it was obvious that they enjoyed their work. 


\section{The School}

The Kawasaki Kindergarten (pseudonym) was built in 1955 in Kawasaki City, Japan. It has one classroom for 3-year-olds, three classrooms for 4-year-olds, and three classrooms for 5-year-olds. The enrollment fluctuates around the 200 level while the teaching staff consists of eight full-time teachers, the director, the assistant director, the helper to the assistant director, and the school van driver. Additionally, on a part-time basis, an art teacher, a gymnastic teacher, an accountant, and a special education teacher are employed by the school. The school is privately owned and run by the director's family, and the director's mother is his assistant director.

\section{Settings}

One cold blustery morning in February of 1992, I entered the front gate of Kawasaki Kindergarten located in the busy, heavily industrialized city of Kawasaki. The gate opened into a spacious playground made of sand, flanked on the right by monkey bars, a jungle gym, a climbing structure shaped like an airplane, a gymnastic structure for climbing and swinging on, another climbing structure that had both a net made of chains and a ladder for the children to climb on, as well as large hoops and squares that could be used as swings. Just beyond this structure stood the facade of a brightly colored fantasy castle behind which the children's outside play toys were stored. To the left of the playground, there was a rustic log cabin which left the impression of an oasis in the middle of this industrialized metropolis. The log cabin itself stood elevated on heavy log stilts with stairs leading up to it. Inside was an old fashioned wood-burning stove, a wooden table and chairs, cooking utensils, as well as cleaning equipment the children could use after their play. Also provided on the second floor of the $\log$ cabin were wooden beds for those with sleepy heads. The space beneath the cabin served as a parking place for the school van. There was also room beneath for a small playhouse with one entrance that was also constructed of logs.

Behind the $\log$ cabin was a white two-story building, called the tea room, that contained rooms for the children's computer studies and meeting rooms for parents. To the right of the tea room was 
the main building. It was a large, two-storied white building with a flat top, housing three rooms at the lower level and four at the upper level. To enter the lower level, I passed under a large slightly arched porch in the center of the building where children removed their shoes and put on tennis shoes to wear inside. Shelves were provided for the children's shoes under the arched porch. On the extreme left and right sides of the building at the front were two smaller porches that protected two sinks, each with four faucets on the outside, and there were a corresponding number of faucets connected to the same sinks on the inside of the building. Children could use the outside sinks to wash off before entering the building, and the inside sinks could be used before lunch.

On the outside of the building, a flight of stairs with protective railings that led to the second floor began next to the left outside sink. The sides of the stairs facing the playground were decorated with pink bunnies hopping all the way up to a ledge located over the large curving porch. The ledge was decorated with a red and orange bunny house in the clouds containing a number of bunny dwellers. The bunny stairs were only for emergency use. The bunny house ledge provided access to two sliding doors that opened onto the second floor. Sliding windows were situated all the way around the top floor providing plenty of daylight for the classrooms.

When entering under the arched porch, shelves for shoes were provided on a walkway that extended the length of the arched porch from the porch area to inside the building itself. To the right of the walkway and the three downstairs rooms, a flight of stairs led up to the four rooms on the second floor; these were the classrooms for the 6-year-olds. All these classrooms were furnished in almost the same manner. Each classroom had two doors situated on the left and right sides of sliding windows that were centered at the front of the classrooms. The doors provided access to the classrooms from the halls that connected them. When entering each of these classrooms, I found that on the entire length of the left wall was a display board on which the children's artwork was shown. On the length of the right wall was a blackboard. Beneath this blackboard toward the back of the classroom, a small door which was kept open almost all the time by a hook, connected each classroom. Children could crawl 
through it into the adjoining classrooms. This door was provided as an escape in case of an emergency although the children found it more useful for play than for the purpose for which it was designed. In each of the upstairs classrooms, I found a piano, an organ, bookcases, a cupboard, a variety of stuffed animals, and two or three baskets full of blocks and plastic toys. In none of these classrooms did the teachers have desks. Each child had a shelf with his or her name on it with a box containing crayons and a pair of scissors, another box containing clay, a plastic board upon which to model the clay, a large drawing book, and a workbook. Next to each child's shelf was another shelf used to store his or her hats. Two different hats were provided for the children, one for coming to school or going home, and the other for going outside of the school, exercising or playing outside. Each child shared with another child a small open cubby in which to hang his or her belongings. Generally, each classroom had four to six tables which were made by putting five or six desks together to form each table.

Three classrooms for 5-year-olds were located downstairs. They were furnished in the same manner and were provided with the same materials as the classrooms for 6-year-olds except there were no organs, and there were kitchen toys for dramatic play that were not found in the upstairs classrooms. The children in the downstairs classrooms were provided with the same kinds of shelves in which to store their art materials and hats. They also hung their belongings in the open cubbies that they shared with others. Here each classroom had three or four tables made by putting desks together and each table had seven or eight chairs around it. The rooms had sliding glass doors.

Adjoining this building next to where the stairs were located was another building containing a large hall where children played, exercised, and had various ceremonies. A bathroom was provided at the rear of the hall for the children. Adjacent to the bathroom was a classroom for the youngest children (3-year-olds), and next to this classroom was a storage room for teaching and art materials approximately the same size as the classroom. This row of three rooms was visible from the large hall. The office was in a room about one third the size of the hall and approximately equal to the combined size of the classroom for the 3-year-olds and the storage room. The bathroom, storage room, and the 
classroom for the youngest children comprised the area at the rear of the hall, while the office adjoined the side of the hall, comprising approximately two thirds of its length. The front entry to the office was just off the playground and was used primarily by adults. This entry opened into a foyer in which shoes could be removed before entering the office. There was also a sliding door providing access between the hall and the office. The two main buildings described above embraced the playground on two sides in an $\mathrm{L}$ configuration.

My first impression as soon as I entered the gate was that although the weather was cold, there was a kind of warmth resulting from the brightly colored cheerful surroundings, and the happy sound of children's laughter, chirping birds and the cockadoodledoo of the roosters who were residents of the kindergarten. The cleanliness and orderliness both inside and outside the school impressed me greatly. I was also amazed to discover that the school did not find it necessary to hire a custodian because the cleaning was done by the teachers and children. In addition, it was surprising to me that there was a small amount of toys relative to the number of children and that the children were allowed to play the pianos or organs at their whim when not in use by the teachers. Another thing that greatly impressed me was that although land was at a premium in Japan and that the available space was utilized at maximum efficiency, no expenses were spared to assure that the appropriate sized spaces were allotted to maximize the benefits of the classrooms, playground, and other facilities.

\section{One Day at Kawasaki Kindergarten}

The children came to school six times a week except for the third Saturday of each month. On Mondays, Tuesdays, Thursdays, and Fridays the children stayed from 8:30 a.m. until 2:00 p.m., and on Wednesdays and Saturdays they stayed from 8:30 a.m. until 11:00 a.m. The activities were uniform for each classroom of the same age group, thus a description of one classroom is a general description of all the classrooms for that age group.

A typical day at Kawasaki Kindergarten began with the cheerful greetings of the children and teachers. "Ohayo gozaimasu (Good morning!) was heard everywhere I went. Tiny children in their 
school uniforms bowing in unison and saying, "Good morning!" looked like dominoes falling forward to capture the heart.

Some children arrived at school by walking and others came by school van. By 9:50 a.m., all children had arrived. The school van had four different routes to pick up the children and the ones who arrived by school van gathered in one classroom singing songs and playing games according to the directions of an appointed teacher. At 9:00 a.m. those children who were already in school went outside to play. Each time the school van arrived at the playground, the children immediately moved over to the school building to avoid the van. It was like watching a tide rushing in and out as the children all moved away at the announced arrival of the school van and back again when the van left to pick up more children.

When the children arrived at school, they changed their shoes outside and put on shoes for inside wear and went to their own classes to change into their smocks. None of the children whom I saw, including 3-year-olds, had a problem changing their clothes. After changing, they went to a specified classroom or outside to play.

At 9:50 a.m. all children lined up for morning exercise according to their own classroom designations. Since the colors of the children's hats denoted different classes, it was easy for everyone to distinguish where the children belonged. The morning exercise included following musical directions while engaging in activities of jumping, clapping hands, stretching, turning, and running in place. By 10:00 a.m. exercise was over and the children were instructed to stay in line and to go to their own classrooms. Before they entered their classrooms, everyone washed their hands and gargled. Those children who needed to go to the bathroom were allowed to do so.

My observation inside the classroom of 5-year-olds began with the teacher playing the piano and the children singing the morning song and then the school song. After the songs, everyone greeted each other by saying, "Good morning". The teacher called the roll and asked the children, "Who are the tobans today?" The tobans are those persons chosen daily on a rotating basis to help in the 
classrooms and are responsible for giving the children vitamin pills and stickers to put on their date books to indicate their attendance. The tobans usually consist of two children, one boy and one girl, and everyone has a chance to be one of the tobans for the day.

By the time they finished their morning greetings and choir, it was about 10:40 a.m. and the teacher announced the activities of the day for the classroom. This particular day the children were instructed to draw pictures of subjects of their own choosing. This drawing time lasted until 11:30 a.m. The teacher then played the piano theme signalling that it was cleanup time. After cleanup, the children started preparing for lunch by washing their tables with wet cloths, washing their hands, and taking their lunch boxes from their yellow bags.

By 11:50 a.m. every table had been decorated with the children's bentos (lunch boxes) all laid out in an orderly fashion. When the cloth wrapper that had secured each lunch box had been unfolded, the box was placed with chopsticks, spoon and drinking cup in the appropriate locations for each upon the cloth. Lunches had been brought from home in plastic boxes or aluminum boxes decorated by cartoon characters. Food had been prepared in such a way as to appeal to the eye as well as the palette; carrots were sculpted into the shape of flowers, and dessert, usually consisting of fresh fruit, included apples that were cut in such a manner that they had the appearance of bunny ears. No peanut butter and jelly sandwiches in plain brown paper bags for these children. An example of a bento that I observed consisted of fried cod fish cut into small bite-size pieces, buttered sauteed spinach, cooked carrots cut into butterfly shapes, cherry tomatoes with lettuce, and quartered boiled eggs. Food items were fitted into the box neatly and precisely like a jigsaw puzzle. Simons (1987) also described bentos as culinary jigsaw puzzles.

When everyone was ready, including the children and teacher, a ritual began when the teacher sat at the piano and began playing the bento song. The song indicated the children's appreciation of their parents' preparation of the food, and the encouragement to eat all the food that had been provided so the children could grow strong and healthy. After the song, everyone chanted in unison the formal 
announcement for beginning the meal, "Itadakimasu" a word that encompasses the meaning of "Thank you for the food, I am going to eat now".

By 12:40 p.m., all chanted the word "Gochisosamadeshita" that translates, "Thank you for the food, it was delicious". Between 12:40 and 1:40 p.m., the children had free time to play inside the classroom except for the children who were still eating. This free time in the classroom consisted of artwork, play dough, books, blocks, and card games. By 1:40 p.m., smocks were hung up in the cubbies and school uniforms were put back on in preparation for going home. The teacher played the goodbye song and everyone joined in singing. After the song was completed, the children all bowed to the teacher and said, "Sensei, sayonara" (Teacher, goodbye), and bowed to each other and bade each other farewell. By 1:50 p.m., all children who were ready to go home had gathered in the hall. While waiting to be picked up by their parents or the school van, they sang songs and played games with the teachers. There were two specific things that lingered strongly in my memory. One was the fact that the children were allowed to wander in and out of the classrooms freely at all times, including visits to the other classrooms. The teachers did not make any effort to prevent these excursions but left it up to the classmates to instruct the wanderers to return to where they belonged. Another thing that amazed me was the use of ritual songs and chants to lead the children in the transitions to new activities, and there was always plenty of time allowed for the transitions to take place. Also, there were no verbal requests for cleanup in this school, instead, music was used to indicate cleanup time and there were no complaints from the children. Although cleaning up appeared chaotic, by the time this tumultuous storm of activity had passed, pristine order was left in its wake. 


\section{Chapter 3}

\section{Findings}

This chapter summarizes the major findings according to the interpretations of the tests, interviews, and observations. The results of the statistical analysis will be presented and the themes that unfolded in the qualitative data will be described. The major themes and the supporting themes will be introduced and elaborated upon.

\section{Statistical Analysis}

A descriptive analysis of playfulness of the 5- and 6-year-old children in this study will be presented as will the results of an examination of the relationship of playfulness to creativity, age, gender, and class.

Teachers in six classrooms rated their students' playfulness using the Child Behaviors Inventory (Rogers, 1988). The means and standard deviations of each class are shown in Table 1. 
Table 1

Means, Standard Deviations, and Statistical Tests by Class, Gender, and Age in CBI Scores

\begin{tabular}{llllll}
\hline Group & $\underline{n}$ & $\underline{M}$ & $\underline{\text { SD }}$ & $\underline{\text { Statistic }}$ & $\underline{p}$ \\
\hline Class & & & & & \\
5-year-olds & & 71.91 & 11.36 & $\underline{F}=8.50$ & .00 \\
Class 1 & 22 & 79.29 & 12.14 & \\
Class 2 & 24 & 90.96 & 8.16 & \\
Class 3 & 23 & & & \\
6-year-olds & & 70.72 & 16.64 & \\
Class 4 & 32 & 74.84 & 15.22 & \\
Class 5 & 31 & 70.59 & 13.03 & \\
Class 6 & 32 & & & \\
Gender & & 74.97 & 15.59 & $\mathrm{t}=.69$ \\
Male & 78 & 76.56 & 14.05 & \\
Female & 86 & & & \\
Age & & 80.82 & 13.13 & $\mathrm{t}=3.87$ \\
5-year-olds & 69 & 72.05 & 15.08 & \\
6-year-olds & 95 & & & .0002 \\
& & & & \\
\hline
\end{tabular}


The results of an analysis of variance across the six classes showed a significant $F(8.50, p<.000)$. An inspection of the means reveals that the mean of class 3 is substantially higher. This teacher consistently gave higher ratings. The statistically significant differences are made up of a reflection of the teacher rather than actual class differences. The results of the two-sample $t$ test on gender showed that these two means were not significantly different from each other $(t=0.69, p=0.49)$.

The results of the t test on age groups showed that the 5-year-old children scored significantly higher on the CBI than did the 6-year-old children $(t=3.87, p=0.0002)$. This may have been due more to the fact that one of the teachers of 5-year-olds scored her students higher than did other teachers. Analysis of variance also demonstrated that there were significant differences among different classes' $(p=0.0000)$ scores on the CBI. Again, differences appear to be related to the higher scores given by the teacher in class 3.

Using a series of $\underline{t}$ tests, creativity was examined in relation to gender, playfulness, and age. Creativity scores as measured by the TCT-DP Test showed no significant differences due to gender $(t=-.58, p=0.57)$.

When students were grouped according to playfulness, scores on the TCT-DP Test were 10.5 $(S D=3.56)$ for the playful children and $18(\underline{S D}=9.96)$ for the nonplayful children. These two means were not significantly different from each other $(t=-1.74, p=0.1131)$ due to the very different standard deviations. However, it should be noted that three nonplayful children scored higher than the playful children did. These results indicated that because these three nonplayful children took longer and put more detail into their TCT-DP Test, their scores were higher than those of the playful children. The I test for the TCT-DP Test scores by the children's ages showed that there were no significant age differences in the means of creativity scores between the 5 - and 6-year-old children $(t=1.19, p=0.2604)$ (See Table 2). 
Table 2

T Tests for TCT-DP Scores by Gender. Playfulness, and Age

\begin{tabular}{llllll}
\hline Group & $\underline{n}$ & $\underline{M}$ & $\underline{S D}$ & \pm & p \\
\hline Gender & & 15.67 & 6.74 & -0.58 & 0.57 \\
Male & 6 & 12.83 & 9.77 & & \\
Female & 6 & & & & \\
Children & & 10.50 & 3.57 & -1.74 & 0.11 \\
Playful & 6 & 18.00 & 9.96 & & \\
Nonplayful & 6 & & & & \\
Age & & 17.00 & 8.07 & 1.19 & \\
5-year-olds & 6 & 11.50 & 7.89 & & \\
6-year-olds & 6 & & & & \\
\hline
\end{tabular}


The scores derived from the Drawing Test (Acharyulu \& Yasodhara, 1984) were also computed using the $\rfloor$ tests. The $\rfloor$ test for the creativity scores showed that there were no significant differences between females and males in the means of the Drawing Test scores $(t=1.64, p=0.1330)$. The $t$ test for the creativity scores by age showed that there were no significant differences between 5- and 6-year-old children in the means of the Drawing Test scores $(t=-1.82, p=0.0984)$. The mean scores of creativity were $15.33(\mathrm{SD}=3.20)$ for the playful children and $13.5(\mathrm{SD}=5.43)$ for the nonplayful children $(t=.71$, $p=0.49$ ) and were not significant. (See Table 3). 
Table 3

T Tests for Drawing Test Scores by Gender, Age, and Playfulness

\begin{tabular}{llllll}
\hline Group & $\underline{n}$ & $\underline{M}$ & $\underline{S D}$ & $\underline{t}$ & $\underline{p}$ \\
\hline Gender & & & & & \\
\hline Female & 6 & 16.33 & 2.94 & 1.64 & 0.13 \\
Male & 6 & 12.50 & 4.93 & & \\
Age & & 12.33 & 4.68 & -1.82 & 0.10 \\
5-year-olds & 6 & 16.50 & 3.08 & & \\
6-year-olds & 6 & & & & \\
Children & & 15.33 & 3.20 & 0.71 & \\
Playful & 6 & 13.50 & 5.43 & & \\
Nonplayful & 6 & & & & \\
\hline
\end{tabular}


The creativity scores derived from the Drawing Test were validated against two artists' ratings of drawings for creativity. Using the Spearman's rho, the ratings obtained by the artists were correlated with those that were computed by the writer in order to validate the test. There was a positive correlation of 0.84 between the scores derived from the writer and the first artist and a moderate correlation of 0.62 between the writer and the second artist. Also, a correlation of 0.83 between the first and second artists indicated a strong relationship. All the correlations were statistically significant and indicated that interrater reliability was acceptable.

\section{Qualitative Analysis}

The following is a discussion of the results of the interviews with the children and teachers, the two tests, and the observations of the playful and nonplayful children. The themes of active leadership, curiosity, creativity, and self-motivation that emerged from the data of the playful children will be discussed and those themes of nonplayful children (passivity, diligence, and internal playfulness) will be described. The teachers' concepts of play, playfulness, and creativity are included in this chapter.

Playful Children. As I analyzed the data, I began to see that among the playful children, active leaders who could initiate things emerged as the major theme. The supporting themes such as curiosity, creativity, and self-motivation emerged. The major theme will be discussed and the supporting themes will be presented here.

These six playful children were considered by their teachers to be active leaders who are capable of initiating activities and of helping others when needed. Five out of the six children were described by their teachers as leaders in their classrooms. Maya, a teacher of a classroom of 5-year-old children commented on her playful student, Yoshiko in the following way:

Yoshiko likes to be in charge of everything. She doesn't like to lose and initiates what she wants to do when playing with others. If she doesn't like the course of play, she will get upset and leave that play...She is like a leader in our classroom.

Mariko described her student, Maiko as follows: 
Maiko is a leader in our classroom. She can help others when help is needed. For instance, when a child was crying, she asked her what was wrong and tried to solve the problem for her. She really likes to help others.

Keiko, a head teacher noted her classroom's playful child, Toyo:

Toyo is a child with leadership qualities who can initiate play and get others to join her. Sometimes she assists me when help is needed or when I am unable to assist another child, Toyo will step in and offer her help.

These children's leadership qualities included the abilities to be active, help others, initiate activities, and solve problems. Some of the qualities discussed by the teachers were found in the six dispositions of play delineated by Rubin et al., 1983, such as active involvement, initiation, and self-motivation.

One of the qualities of leadership, the ability to help others, seemed to be related to these teachers' goals of preschool education as they discussed in the interviews with me the importance of nurturing children's ability to care for others. Yuko, a teacher of a classroom of 5-year-olds, commented on the importance of nurturing children's ability to care for others, "I want my students to develop tender hearts to care for others." Kyoko, another teacher of a classroom of 5-year-olds, discussed the same topic in this way, "Because in today's world people tend to be selfish and don't care for others, caring is very important in our society and I hope that we can nurture this caring attitude in children." Haru, a teacher of a classroom of 6-year-olds, described her goal of preschool education:

I want my students to be gentle and kind to each other...A group life, the interaction with others, being gentle, and caring for others are very important. For instance, when one child sees another child crying, I want this child to comfort the crying one and ask what is wrong.

Curiosity appeared as the first supporting theme among the playful children's data. These children were described by their teachers as being either curious or interested in everything. Maiko, Yoshiko, Shu, and Yuki were considered by their teachers to be curious. Maiko's teacher discussed her 
curiosity, "Maiko is interested in everything, for example, when she sees someone's new ways of making origami, she is the first one to ask about the procedure." Yoshiko's teacher described her curiosity, "Yoshiko is the most curious child in my classroom. She wants to know about everything around her...even what is going on in the next door classroom. You can see her curiosity in her body language and actions." Yuki's curiosity was described by his teacher, "Yuki takes a positive attitude toward everything and is interested in everything." Shu's teacher commented on his interests in everything, "Shu is a very curious child and has to know what is going on around him. He is not shy to ask questions about anything."

Cecil, Gray, Thornburg, and Ispa (1985) stated that curiosity is one of the prerequisites for the manifestation of play. They explained that play is the manifestation of creativity, exploration, and curiosity. "Curiosity is then the arousal state which leads to exploration, play, and creativity" (Cecil et al., 1985, p. 202). When children actively investigate objects, they may be considered as being curious or exploring.

The second theme, creativity, emerged from the data of the playful children. Of the six playful children, four were considered by their teachers to be creative. Creativity included the abilities to create artistic products, to solve problems, and to express many ideas. Ken's teacher described his creativity in two areas, artistic creativity and problem solving skills:

Ken is able to create and express the images in his mind in his art work, especially in drawings. Because of his flexible nature, he is always able to talk about any problem among his friends and solve it nicely.

Maiko's teacher commented on her creativity as the ability to create products from simple materials:

When I give Maiko a piece of paper, she will make an origami out of it, then she attaches a string, writes words on it, and makes a pendant. I think that she is capable of creating unique things from simple material. 
Kazu's creativity was discussed by his teacher, "Kazu has lots of good ideas about arts and crafts, and he really is able to make products that represent his personality."

Some interpretation of the data of creativity in the playful children appeared to be related to the teachers' discussions of the attributes of creativity such as the ability to see things in numerous ways, to use past experiences, to expand ideas, and to express ideas in many different forms. Yuko described her concepts of creativity:

To me, creativity is the child's ability to use materials to make something in a different form. And the creative child can develop play and create new things by using his or her past experiences or learned skills. This child also can create and express his or her ideas of images in some tangible form.

Kyoko's discussion included a cultural attribute:

Creative children are always willing to tackle tasks. They also have yutakana kokoros (generous, courageous, compassionate, moral, and sensitive hearts thus nurturing the child's ability to see the world in a better way). They also have lots of ideas and dreams...creative children can engage in tasks or play actively and also can expand their ideas to the highest level.

Yutakana kokoro is highly valued as one of a "good" child's qualities in Japan (White \& LeVine, 1986) and this quality is encouraged at home and at school. Mariko's comments on creativity included the use of language:

I think creativity can be seen in children's conversations when they are making up stories. It comes from the children. The creative child has a flash of wit and can express it in language, drawings, or any other form.

Regarding the question of how to nurture their children's creativity, these teachers appeared to be describing one main concept: providing an appropriate environment. This environment included allowing freedom and giving hints. Yuko described how she promotes creativity in her classroom: "I 
give my children plenty of materials and an environment that allows them to do things in their own ways. I also try to give them hints or think together with them when they need my help." Kyoko noted the use of language as a way of promoting her children's creativity: I don't tell my children how to create things, but I think I tell them about what we can do about creating or making things. For instance, when we make a bunny for our art activity, I talk to my children about all different kinds of bunnies so they can know about them.

Self-motivation was another theme that emerged from the data of the playful children. The term, self-motivation, included the ability to initiate things (play, activities, and tasks) and to act according to one's own will. Toyo, Yoshiko, Kazu, and Yuki were described by their teachers as being self-motivated children. Toyo's teacher commented on her, "Toyo is a child who can act according to her will. She brings ideas for play activities to her friends and is able to get others to join her." Yoshiko's self-motivation was discussed by her teacher, "Yoshiko will do what she likes to do but won't do anything that she doesn't want to. She makes decisions decisively in play and her friends will follow her. She takes leadership in play." Kazu was considered by his teacher as self-motivated, "Kazu likes to be in charge of pretend play, otherwise he won't like it. He takes initiation in starting play." Yuki's self-motivation was explained by his teacher, "Yuki's actions are not even...what I mean is that he is enthusiastic about kinds of things that he likes to do but he won't even touch any activity if he is not interested." This self motivation seems to be associated with one of the six dispositions of play described by Rubin et al. (1983), which is player domination. These children knew what they wanted to do and dominated play according to their own will rather than being dominated by peer stimuli.

According to the data, these playful children are leaders, and are curious, creative, and selfmotivated. When I asked the teachers about their concepts of playful children, many responded in this way: Playful children are those who can be actively involved in play or activities, who can initiate play, and who can focus on the process rather than the results of play. 
Haru described the playful child's state of mind:

The playful child, I think, is curious and enjoys challenge. This child doesn't worry about the result but puts forth his or her best effort in the process of play. The child who can enjoy play and who has the attitude to get involved in things is playful in my opinion.

Kyoko's comments were similar to those of Haru:

I think that the playful child is interested in everything and can enjoy playing. This child can get involved in his or her play and cares about the process, not the results of play. I think that the active initiation of play is also important for the playful child.

Mariko's responses included a cultural value (freedom under the rules) which was described by Torrance's study of Japanese preschools in 1980, as well as two of the six dispositions of play: The playful child understands and follows the rules and yet can do what he or she wants under these rules. Playful children get involved in their favorite activities...like making things or writing. They initiate what they want to play.

Torrance (1980) reported that most Japanese preschools he observed had rules for just about everything but under those rules children were free to explore and experience their daily lives in school.

Maya, Yuko, and Mariko described the physical manifestation of playfulness in children:

Maya: The playful child gets actively involved and can concentrate on activities. His or her playfulness shows in the bright shining eyes.

Yuko: To me, playful children are able to get actively involved and enjoy what they are doing. Their conversations or words are active and they show smiles on their faces when playing or engaging in activities.

Mariko: The playful child's active involvement can be seen in his or her shiny eyes.

To sum up, according to the data, the playful children were active leaders who could help others, they were curious, creative, and able to motivate themselves. When the teachers discussed the 
playful children's creativity, the attributes of playfulness and creativity (initiation, curiosity, and enjoyment of play) had a large overlap. In order to promote creativity, these teachers provided ample opportunities and environments for children. In addition, cultural values such as yutakana kokoro, and having freedom under the rules were also discussed by the teachers.

Nonplayful Children. Among the nonplayful children's data, the themes such as being a follower, having diligence, and possessing internal playfulness emerged. These themes will be discussed in that order.

All six children were described by their teachers as children who tend to be passive and follow other children in play. Jiro's teacher commented on his passive nature, "Jiro is a passive child who follows others, so if he plays with quiet friends, he is quiet, but if he plays with active children, he can be active." Tamiko was described by her teacher as a child who tends to copy what other children are playing and who always asks permission to do anything in the classroom. Hide's tendency to follow other children was explained by his teacher, "Hide is a follower in play, especially among three good friends. Because of these good friends, I think he seems to be happy but other children tend to pick on him and he can't even tell me about that." Saiko was described by her teacher as a child who can not initiate play and she said this about her, "Saiko tends to go along with other children. She tends to play alone and copies others if she plays with them."

Diligence was another theme that emerged from the data of the nonplayful children. All six nonplayful children seemed to be hard workers even though they took longer to accomplish their activities, and their teachers agreed with my assessment. Jiro's teacher praised his diligence in this way:

Yes, Jiro is a hard worker and does things till the end, he doesn't give up on things in the middle. It may take longer for him, compared to other children, but he will finish things once he has started.

Shu's diligence was described by his teacher, "Shu gets involved in things when he finds them interesting and he works very hard at them." Tamiko's tendency to work hard at different activities was delineated 
by her teacher, Tamiko works hard at her tasks and can concentrate on them. She is a quiet child but really puts effort into her tasks."

Internal playfulness emerged as another theme from the data of the nonplayful children. Although these six children were rated by their teachers using the CBI (Rogers, 1988) as nonplayful, the teachers did not necessarily consider these children to be nonplayful. For example, two teachers, Maya and Keiko, discussed children's subtle way of being playful. Maya stated that "Children may not look playful by their actions or behavior but if they can express their images in words, pictures, or some other form, they are playful to me." Keiko commented on internal playfulness:

Being playful all the time may be...you see, tiresome to some children so the child watches others play, thinking, 'I can play like that' and this could lead to the child's next play, so I would consider this child to be playful.

These teachers appeared to be discussing the child's internal playfulness rather than external behavior. Two teachers, Maya and Yuko, commented on this topic:

Maya: Even if children don't seem to be playful outside, they may be playful internally and might have imagination deep inside of them.

Yuko: In some ways, playful children may be creative...but even though the child may not be playful on the surface, this child may be creative in drawing, or playing with play dough, so creativity and playfulness could be seen in places where we don't even think of it.

The nonplayful children exemplified by Tamiko and Hide showed great enjoyment during the TCT-DP Test and interviews. During the TCT-DP Test, Tamiko's enjoyment was obvious as she was humming and smiling while taking the test, and she was able to explain everything she did and what was in her mind while she worked on the test. It seemed that Tamiko works better in a one-to-one situation than in a large group since she did well on the TCT-DP Test. She was comfortable enough to move 
around the table that she was working on and asked many times if it was okay for her to work on the test longer.

During the interview, Tamiko responded to my questions willingly and enthusiastically. Her favorite activity in school was drawing pictures. She wants to be a bride when she grows up and she thinks the reason she entered school was because it looked like fun. My last question to her was if there was anything else she would like to tell me, and she jumped up, and in while still in flight shouted, "Yes!" and after an abrupt descent, continued talking. She kept asking me questions like, "Why doesn't the roof of the house move?", and "Why don't we see the moon in the day time?", and "Why is the heater warm?", and "How does a flower grow?" I asked, "What do you think?" in response to her questions and she answered all her own questions saying, "Because the roof can't move by itself," or "Because the sun is blocking the moon," or "Because we turn the switch on." While she was asking and answering these questions, Tamiko was giggling and smiling. While she was looking at my video camera, she asked me an interesting question as to why we take videotapes. I asked her what she thought and she said, "Because we can go to the dream world." I asked her again, "Can we really go to the dream world?" Tamiko answered, "No, we can't because when I said that to some girls, they told me that I was a liar, so I guess we can't go..."

During the TCT-DP Test, Hide seemed to be enjoying himself as he talked about the test in response to my asking him what was in his mind while he worked on it. For example, he related his test to the big earthquake that had occured just a couple of days before, smiling and joking about it. His sense of humor was observed not only during the TCT-DP Test but also during the interview as he talked about his favorite shows on TV, smiling and giggling. One of the most popular cartoon characters in Japan at present is an Anpan Man (a man made of sweet beans and bread), and Hide humorously explained the whole story about the Anpan Man show. Interestingly, his favorite thing to do at home was to watch cooking programs on TV. 
I could not help noticing the warm smile on his face and his polite manners while talking to me during the test, the interview, and the observation. I felt comfortable being with him because of his constant smile that became even wider when he was with his friends. During the observation, Hide sat nicely in his chair and worked on a drawing of his own face. He had his face down on the paper, focusing diligently on what he was doing. He looked up and told me to come see the drawing of his face. When I saw the drawing, I asked him what was on the nose in the drawing (it looked somewhat like a long line) and he told me that it was a drawing of him sneezing.

According to my observations of the nonplayful children, it appeared that they were quiet, showing little interaction with others while engaging in their tasks in the classrooms. Although the teachers rated them with the CBI as nonplayful, some of these children were observed to be playful in a one-to-one situation. According to Rubin et al. (1983), play can be defined by context, behavior, and disposition. During my observations, none of the nonplayful children received their teachers' attention as they were quiet and were busy while working on their tasks. They mostly blended in with the other children in the classroom and this made it harder for me to find them.

In summary, according to the data, the nonplayful children tended to follow others in play, to work hard at given tasks, and some seemed to possess internal playfulness. And in terms of playfulness, two nonplayful children exhibited a great sense of humor and enjoyment of activities in the context of a one-to-one interaction.

Both Playful and Nonplayful Children. In order to understand these 12 children's concepts of school, I asked about their other activities outside of school and about their plans for the future. All the children's responses regarding their favorite things to do in school were related to play. All of them were able to specify what kind of play they liked with the exception of one child. The children described a variety of activities as being their favorites, and drawing pictures was the most popular activity for these children. Other favorite activities included physical exercise, soccer, video tapes, books, play dough, sand play, and playing with animals. 
While discussing their least favorite things to do in school, everybody was able to verbalize that those activities were uninteresting or tiresome. They included arts and crafts, sitting in their chairs, playing with blocks, clean up time, snow play, and just being in school. Interestingly, the children who responded that there was nothing that they did not like about school were all girls. However, Yoshiko responded directly and openly:

Q: Tell me about your least favorite things to do in school.

R: (Without hesitation) Clean-up time!

Q: Why?

R: Because it makes me tired.

Q: But you have to do it, right?

R: No, I get away with it.

Q: How?

R: It's easy, I just run away.

The reasons the children gave for attending school appeared to fall into two groups: to play and to learn. According to Yoshiko, growing up is one of the reasons why children go to school. She stated, "When we grow up, we go to kindergarten because it is a shame to stay a baby." Mimi's responses included the Japanese cultural theory of learning of ganbaru (persistence, do not give up), "I go to kindergarten because everyone goes there so I go ganbatsute (I go to school with persistence). Many researchers (Duke, 1986; Hendry, 1986a; Simmons, 1990; Singleton, 1989; White \& LeVine, 1986) referred to gunbare as a Japanese cultural theory of learning. Japanese, generally, are encouraged to do their best and not to give up easily when starting tasks or activities. This spirit of ganbare starts at home and the school takes it up when the child enrolls (Duke, 1986).

All these children, with one exception, responded that they all prefer playing with other children rather than playing alone. Yoshiko revealed her methods of play with others: 
Q: Tell me about your friend(s) at school. Do you like to play with them or do you like to play by yourself?

R: Well, I like to play with girls but we usually end up fighting. Then later we become friends again.

Q: How?

R: When we play together, kokoroga tokeru (our hearts melt).

Q: Kokoroga tokeru?

R: It means that your hearts become warm and you understand others' hearts and you don't fight anymore.

The children's responses to the question, "What do you want to be when you grow up?", seemed to be associated with romanticized aspirations, relating to entertainment, public service, and merchandising. Their responses regarding hopeful occupations included a baker, a bride, a flight attendant, a fruit stand owner, a police officer, a baseball player, and a jet coaster operator. From their occupational aspirations, I inferred that these children might be thinking of occupations that are familiar and dramatic to them and that they might be identifying themselves with their romantic notions about these occupations. Yoshiko specified her occupational aspiration:

Q: What do you want to become when you grow up?

R: I want to become a flight attendant.

Q: Why?

R: Because they look cute.

Goodman's study (1957) compared Japanese and American children's perceptions of occupations in elementary school grades 1 through 8 . The study found that younger children in both nations tended to choose occupations that they are familiar with.

Hendry (1986b) reported that a high number of preschool children in Tokyo attend some kinds of classes to develop certain skills and I wanted to find out about this fact from these children. When 
I asked the children if they took lessons outside of school, 8 out of 12 responded that they were taking some kinds of lessons. These included calligraphy, kumon (the study of numbers), art, swimming, English, and piano. Two girls, Yosiko and Toyo, told me that they take either English conversation classes and swimming, or piano and calligraphy. It appeared that these lessons were related to culturally valued skills. Calligraphy, Kumon (the study of numbers), and English conversation were typically popular lessons among these children. In addition, both calligraphy and Kumon focus especially on training the formalized and structured skills of concentration, discipline, and diligence which are valued by the Japanese culture (Hendry, 1986b).

In short, it seemed that these children considered preschool to be the place where they play and learn. They all responded that they enjoyed playing with other children with the exception of one child. The girls tended to enjoy preschool more than did the boys. One child mentioned the Japanese learning norm of ganbare (don't give up) as the reason for going to school. Their aspirations for future occupations seemed to be related to their immediate familiar occupations. Of 12 children, 8 responded that they take lessons outside of school, and this learning involving skills of concentration, diligence, and discipline outside of preschool is a new trend.

Playfulness and Play. Assessing children's playfulness using the CBI seemed to be valid because the evaluation by the teachers, Ms. O, and me coincided with the results of the CBI. For instance, Ken was described by his teacher in this way, "Ken enjoys playing with other children inside as much as he enjoys outside activities such as tag play or running around". My observation of him during clean-up time seemed to confirm the assessment of his playfulness by the CBI. Ken, during clean-up time, held a small box in his hand and got on the floor and began picking up pieces of scrap paper one by one. He made a game out of picking up trash by sliding around the floor, counting his pieces of paper, and smiling and talking to himself. While he was sliding around on the floor, he found a smock. He picked it up and read the name tag aloud, looking around. When he found the owner, he went to her and said, "Here, this is yours." He smiled and handed the smock to the owner. The girl said, "Thanks." Then 
Ken returned to the floor and began sliding, picking up pieces of paper and counting them. Other boys joined Ken in this cleaning activity. As Erikson (1972) and Millard (1974) considered playfulness to be one's attitude toward approaching his/her tasks, family, friends, etc, Ken's positive attitude toward cleanup time seemed to come from his playfulness.

Toyo was playful according to the comments made by her teacher and Ms. O, and I also observed her playfulness during art activity. Toyo's teacher commented on her as follows:

Toyo is genki (healthy, active, spirited, and energetic), akarui (cheerful and bright), and has a big voice, thus, she can get attention easily. She is able to act according to her will. She also has good ideas about play. For instance, when I started playing tug of war with two children, she suggested that it would be more fun to play the game with more than two children.

The assistant director, Ms. O, also described Toyo as an akarui (cheerful and bright) and playful child. The words genki and akarui are used to describe the attributes of a "good" child in Japan (White \& LeVine, 1986). Also, a big voice in a child is considered to be a positive attribute because that means that the child is capable of self-expression and can say things loudly and clearly. For example, greetings such as "Good morning", "Good-bye", and "Thank you" should be spoken clearly and loudly.

My observation of Toyo with her friend during art activity confirmed the description of her by her teacher as a child with good ideas about play. During the time for arts and crafts, the art teacher instructed the girls to wait and watch while the boys were building playhouses. While Toyo and three friends were sitting on the floor, watching the boys working, she initiated a skillful game that involved clapping hands with her friends, with movements that were reminiscent of those of a drill team. Two girls teamed up and competed with each other during this game. Afterwards, Toyo got up and started dancing. Then she started to hold hands with the girl next to her, singing the song called "Kagomekagome." This song is sung when children play a game hundreds of years old, involving one person sitting with eyes covered by the hands surrounded by a group of friends circling around the 
person sitting in the middle, singing "Kagome, Koagome..." When the song finishes, the circling children stop and sit down suddenly, and the child in the center has to guess who is sitting directly to the rear. Toyo and her friends repeated this game many times and other girls asked to join them. Shortly thereafter, two more groups of girls who were waiting for their turn to do arts and crafts started playing the game by themselves. At this time, the singing and laughing of many girls were to be heard.

Yoshiko was viewed as playful by her teacher, Ms. $O$, and me. Her teacher described her playfulness in this way, "Yoshiko plays well, can initiate play and enjoy herself." Ms. O commented on her in much the same way as Yoshiko's teacher, "Oh, she surely knows how to play and enjoy herself."

I also observed her helpfulness and curiosity during lunch time. Yoshiko sat at the table with five other girls, and the girl who sat next to her could not finish her lunch. This girl appeared bored as she looked at her lunch box, and seemed uninterested in finishing it. Yoshiko looked at her and asked, "What's the matter with you? Can't you finish your lunch?" The girl said, "No." Yoshiko said to the girl, "Tll tell the teacher for you." Yoshiko got out of her chair and went to the teacher who was at the piano. She told the teacher that her friend could not finish her lunch. The teacher said to Yoshiko, "As long as she tries, it's okay for her to not to finish." Yoshiko jumped back to the table and told the girl the good news, helping her to put her lunch box away. Then she looked at me and asked:

Q: Did you see Daijobura last night?

R: What is that?

Q: You know, that cartoon, don't you know?

R: No, I didn't see it.

Q: Did you see Anpan Man (a cartoon character)?

R: Yes, I saw it once.

Q: You mean you saw it in America?

R: No, I saw it here, in Japan.

Q: Do you have two houses, one in Japan and one in America? 

R: Yes, can you come and visit me?
Q: Well, I don't know what to do there. What can I do there?
R: I will be there and you can visit me, right?
Q: That's true...I'll be there. But not right now, okay?

Another playful child, Maiko, was also viewed as being playful by her teacher as she described Maiko in this way, "Maiko enjoys playing anything and is able to modify her play from sand box to badminton to Chinese jump rope. Her play changes from one moment to the next."

During the course of analyzing the responses made by the teachers regarding play, I started to notice that play as a learning opportunity was emerging as a major theme. The attributes of their responses seemed to relate to children's social, cognitive, and physical development:

Q: Tell me how children's play in preschool should be.

Maya: I think that at preschool, there are children and teachers and we play together and learn to care for others. Through a group life, children learn to play together, thus, play helps in their development. Play is one of our basic needs. Through play children develop their physical and cognitive skills, learn cooperation, find their own ways of doing things, and understand the consequences of winning or losing a game. Of the same question, Mariko commented:

Children should be able to play and interact with children of all ages and pick up ideas from each other as well as teachers, and use and expand them.

Haru's responses expanded my interpretation of the other teachers' responses:

The child should not be worried about a certain way of doing things but should be able to change, adapt, and be flexible in play. Thus, a boy can be a father one day and the next day he can be a mother. Children need to experience play with their bodies. It is okay even if they get dirty. They need to explore, for example, through playing in sand how they can play with or without water. They need to get their hands on things. 
Keiko discussed the developmental stages in play:

Play should develop according to the children's ages. First, the child may be playing alone, then playing with others. It can be said about the content of play, for example, when playing with sand, children enjoy playing with lots of other children and that is why the interaction between the child and other children is important in play.

Yuko also commented, "I want children to learn the pleasure of playing with other children and enjoy a group life. Play provides this opportunity for them."

The child's initiation in play appeared as another theme. The following responses by the teachers lent credence to this interpretation:

Kyoko: It is important for children to be able to play the way they want to. Of course, there are limits to what they can do, but they should be able to choose materials and use them when and how they want to.

Yuko: Play should come from the children and not from the teacher. I think it's so important that they initiate their own play and enjoy it. In other words...when children engage in pretend play, they should decide the settings and the course of play.

In sum, the six playful children identified by the CBI were also considered by their teachers, the assistant director, and me to be playful. The teachers and Ms. O. used the Japanese terms akarui and genki, cultural values that epitomize the "good" child described by White and LeVine (1986). It seemed that the teachers consider that children develop social and cognitive skills through play in a group environment.

Creativity and Playfulness. It seemed that the attributes of playfulness found in the six playful children are closely related to those of creativity. These attributes consist of the abilities to solve problems, to create things according to one's imagination, and to have good ideas. To illustrate, Ken was described by his teacher as a child who can solve problems and can create things according to his imagination. His teacher commented on Ken as follows: 
Ken creates many forms in play dough according to the images of his imagination. When he has problems with his work, he is able to ask his friends or me for help. $\mathrm{He}$ is not only capable of creating art work but also of helping others because he finishes his work quickly. When Ken and his friends are having problems, he tries to solve them by finding out the causes.

The description of Toyo by her teacher as a child with good ideas about play as well as her playful behavior that I observed appeared to be associated with creativity. I observed Toyo elaborate on her play during art activity when the girls had to wait for their turns to participate in hammering play houses. She initiated play, enjoyed it, and most of all, she and the other children were able to amuse themselves rather than sitting and doing nothing while waiting for their turns. According to Vygotsky (1930/1990), creativity exists when imagination combines, changes, and creates something new. He considered imagination to be the basis of any creative activity. Torrance (1977) claimed that some degree of creativity occurs whenever problems are solved.

When I asked about the relationship between playfulness and creativity, the teachers seemed to beleieve that the playful child may be creative but they did not elaborate on their thoughts. However, one key pattern emerged from their responses. Internal playfulness was discussed:

Q: Some studies show that playful children may be creative; tell me, what you think of these findings.

Maya: Yes, I think they are. When children are playful, they are active and can use a lot of imagination. But even if they don't seem to be playful outside, they many be playful internally with lots of imagination.

The same question was discussed by Yuko:

The playful child may be creative and even though the child may not look playful, this child may be able to be creative in drawing or playing with play dough, so creativity and playfulness could be seen in places where we don't even think to look for it. 
It is important to note the internal playfulness discussed by the teachers. Because Vygotsky defined imagination as the internalization of children's play (Smolucha \& Smolucha, 1986a), children may be internally imaginative and this may not be externally observable, thus it may not be measurable. However, this does not mean that they are not playful or creative.

To recapitulate, according to the interpretation of the data regarding playfulness and creativity, the attributes of playfulness and creativity were found to be closely related. Additionally, the teachers described the playful children as creative because these children were perceived by the teachers as being able to solve problems, having good ideas about play, and creating things according to their imagination. Internal playfulness was again discussed by the teachers when I asked them about the relationship between playfulness and creativity.

School Environment. Because creativity can be fostered by certain conditions and environments (Rogers, 1962; Wallace \& Kogan, 1965), an understanding of these 12 children's school environment is crucial. Therefore, I asked the teachers about their concepts of roles and goals of preschool education. The discussion of school environment included the themes that emerged from the teachers' interviews, those being harmonious human relationships, a group environment, and moral values. The teacher interviews are shown in Appendix D.

As I listened to the teachers and read their written subsequent answers, the major theme regarding socialization (harmonious human relationships) began to emerge. This major theme and the supporting themes are presented.

I consistently opened my teacher interviews with the statement, "Tell me, what the most important things for children to learn in school are." The responses to this statement tended to lean toward a discussion of the attributes that would foster harmonious human relationships. These attributes included nurturing a sunaona heart (cooperation without abandoning one's own will), preparing for a group life, caring for others, and developing cooperation. The head teacher, Keiko, responded without hesitation, "To be gentle!" and she also added this comment, "The child is born with 
a sunaona heart and this should be nurtured. We need to develop this sunaona heart by guiding the child. I want to cherish this in children." Of this question, Yuko, the teacher of a classroom of 5-yearolds commented, "I want them to learn the pleasure of playing with other children, to enjoy a group life and to learn the everyday habits of taking care of themselves, such as toileting, eating, etc..." Kyoko, another teacher of a classroom of 5-year-olds, discussed the same topic of learning to be thoughtful of other people. This major theme of harmonious human relationships coincided with the findings of Shigaki (1983) who interviewed teachers from 14 preschools in Japan and found that harmonious human relationships were invariably valued by the teachers.

Group environment emerged as a second theme when I asked the teachers about the necessity of preschools in society. Their responses emphasized the importance of providing an environment where the child can develop as a whole person in a group situation. Maya, the teacher of a classroom of 5year-olds noted, The preschool is the place where children become independent and learn to work as a group and find their positions in the group...and I would like children to spend the preschool life nobinobito (carefree or feeling at ease)". In addition to the importance of a group environment, Maya included the cultural value (nobinobito) which is often used in parental or educational aspirations. Hendry (1986a) described nobinobito as follows:

A word...which means carefree or a feeling of ease, which seems to be gained through an early understanding of how to interact with others so that this becomes as natural as possible, and the child feels free to play without worrying about petty concerns. (p. 121)

Kyoko described the importance of play in a group situation, "Children of the same age play and eat together and learn to be a member of a group. They make friends and learn to be cooperative." The discussion by Haru, the teacher of a classroom of 6-year-olds, elaborated on these teachers' responses, "The school is the place where a child develops as a whole person. Early childhood education is very important because it builds the child's future. It is where children develop their basic skills." 
Another theme, the educational goal for a balance between groupism (a term used by Tobin, Wu, \& Davidson, 1989a) and individualism, seemed to become apparent in the teachers' responses. Although the importance of groupism was frequently mentioned by the teachers, they also seemed to consider individualism to be important. Maya's comments represented this balance:

I want my children to be able to express themselves, but they need to be able to learn

to be a member of a group. I also want to nurture each child's individual positive traits and talents. I want them to be at ease in a group.

Mariko also associated individualism with groupism, "I hope children are able to do things by themselves. For example, when children have problems, I hope that they can work it out among themselves by talking to each other."

Moral values emerged as another theme from the teacher interviews. I began to notice this pattern when I asked these two questions: "What kind of child are you trying to nurture?" and "What kind of experience do you want to give to children?" Although these questions were asked separately, there seemed to be a remarkable consensus among these teachers regarding moral values. In response to these questions, they talked about qualities related to gentleness, caring, kindness, cooperation, genki (mental and physical health), and sunao (cooperation without abandoning one's own will). These qualities in the child appeared very important to Haru:

I want my children to be gentle and kind to each other. I want them to experience and learn that when one child can't do a certain thing by himself or herself, he or she can do it with other children.

Two qualities mentioned previously, sunao and genki, which are considered very important in children by most Japanese (White \& LeVine, 1986) were discussed by Kyoko, "I want children to be caring, kind, and genki," and by Keiko, "I would like children to be sunao and to be gentle to each other."

This pattern of moral values also appeared in their discussions of the quality of a "good" teacher. The qualities mentioned by these teachers seemed to be classified into three categories: the 
ability to listen to children, the ability to provide an appropriate environment, and the teacher's positive mental condition and physical well-being. Keiko's description of the qualities of a good teacher were more likely to include all three categories:

The teacher who is genki and who can oversee all the children in the classroom, the teacher who is ningenrashii (human-like) and sunao, also, the teacher who is able to to see things calmly and understand even those things that the child is not able to verbalize. I like to let my children know my feelings and grow together with them as human beings...I value skinship (close relationships between adults and children). I put everything I have into being with children.

Ningenrashii is the most valued quality among the Japanese because they consider that ningenrashii people (good social persons) can maintain harmony in human relationships (White, 1987). Another culturally valued term, skinship, was described by White (1987) as "A Japanese phenomenon, which they call 'skinship' is the closeness one experiences by touching, preferably skin to skin" (p. 36). Boocock (1991) also explained skinship as being traditional care of infants and young children with physical and emotional contact between the child and care giver.

In short, the teachers considered that the preschool environment should be the place where children learn harmonious human relationships. In order for this to occur, the preschool provides a group-oriented program with an emphasis on play where children learn to cooperate with each other through play. The teachers also considered that they need to nurture and instill Japanese cultural values (sunaona kokoro and nobinobito) in children. 


\section{Chapter 4}

Conclusions

In this chapter, the conclusions reached with regard to the relationship between playfulness and creativity among a sample of Japanese children will be discussed. The results of both quantitative and qualitative data will be presented and the themes that emerged from the data will be related to the review of literature.

According to the results of the statistical analysis, there was no relationship between playfulness and creativity in the Japanese children in this study. This may be related to the fact that my study focused on the artistic creativity of Japanese preschoolers; however, both scales used for measuring creativity assess only limited components of creativity.

The use of the CBI seemed to be reliable in identifying playful children because the six children identified as playful by the scale were unanimously considered by the teachers, Ms. $O$, and me to be playful. However, the results of the data revealed that some nonplayful children were found to be playful internally. This seemed to be related to the fact that the CBI was based upon the western concept of playfulness which is oriented toward the individual rather than the group orientation found in the Japanese culture. Therefore, given the group-oriented programs of the Japanese culture, the teachers are able to identify children's external behaviors using the scale but may not be able to identify their internal playfulness within the context of these group-oriented programs.

The six playful children were found to be active leaders, as well as curious, creative, and selfmotivated individuals. The attributes of active leaders included the ability to help others, and this relates to one of the goals of Japanese preschool education which is to care for others. The teachers' responses regarding the school environment indicated that they want to nurture children who can care for and cooperate with other children.

Included in some of the approaches of achieving this goal described by Lewis (1986a) were: minimizing the impression of the teacher being in control and delegating authority to children. These 
approaches were related to the conditions which foster children's creativity discussed by Rogers (1962), for example, internal locus of control and psychological safety and freedom. The first relates to one's internal rather than external evaluation, and the latter is unconditional acceptance of the individual by others. When the teachers discussed the school environments with me, they mentioned the importance of making the preschool a place where children can be nobinobito (carefree or at ease) and these environmental conditions seemed to be related to those which foster the creativity described by Rogers (1962).

Curiosity seemed to be related to both playfulness and creativity. Cecil et al. (1985) claimed that curiosity leads to exploration, play, and creativity. Rogers (1962) stated that the ability to toy with and explore elements with a playful and spontaneous juggling of meanings are associated with creativity. The six playful children in this study were certainly found to be curious.

The teachers' descriptions of the six playful children as creative may be related to the fact that when they discussed the children's creativity, they tended to talk about their global concepts of creativity rather than artistic creativity.

It seemed that Kawasaki Kindergarten promotes the development of creativity in children because it subscribes to a play-oriented, relaxed, and nonacademic program in a context of group orientation. In October of 1987, Torrance discussed with me the importance of this group cooperation in creativity. He claimed that children's creativity is at its highest when they cooperate with each other. During the teachers' interviews, many teachers also discussed the importance of a group environment in preschool education. For example, one teacher noted that "Preschool is the place where children of the same age play together and eat together, and learn to be a member of a group." Thus, the school environment seemed to be providing ample opportunities for the children to develop their creativity through group orientation.

Self-motivation was another pattern that emerged from the data of the playful children. Amabile and Gitomer (1984) and Kinsey (1984) stated that intrinsic motivation promotes children's 
artistic creativity. This study found that these six children possessed intrinsic motivation and the teachers indicated during the interview that they provided the opportunities for the children to take the initiative and instigate the activities themselves.

The themes that emerged from the data on the playful children appeared to be closely related to the attributes of creativity, curiosity and intrinsic motivation.

Another interesting theme that emerged from the data was the internal playfulness discussed by the teachers. They regarded children's playfulness not only as being overt behavior but also as internal thought (imagination). Maya's comments best described this concept of internal playfulness, "When children are playful, they are creative and can use a lot of imagination. But even if they don't seem to be playful outside, they may be playful internally with lots of imagination." Vygotsky's $(1930 / 1990)$ theory of creativity claimed that imagination is the internalization of children's play, is based on reality, and is a necessary part of any creative activity. In addition, Singer et al. (1980) found that the observed imaginative play of children seems not to be related to their inner creative tendencies. Thus, children's internal playfulness is not easily observed or measured and there seems to be a need to develop methods for measuring internal playfulness.

Another important concept is the way the Japanese think of creativity, for instance, Lewis (1986b) claimed that in terms of achievement, originality is not valued in Japan the same way as in the United States. In Japan, persistence is the key to a successful school life, whereas in the United States, originality is one indicator of successful academic achievement (Azuma, Kashiwagi, \& Hess, 1981; Lewis, 1986b). This persistence seems to be associated with the Japanese theory of learning called ganbare (persistence, don’t give up) discussed by many researchers (e. g., Duke, 1986; Hendry, 1986; Simmons, 1990). Because Japanese historically believe that anyone can be successful through education (Nagano, 1984), the ganbare theory is instilled in children by their teachers and parents.

The reasons for the playful children's creativity scores being lower than those of the nonplayful children seemed to be related to the TCT-DP Test used in this study. Many children seemed to be 
uncomfortable being in an isolated room with me and my videotape equipment. To illustrate, while I was giving Toyo the TCT-DP Test, she appeared to be uncomfortable, her attention wandered, and she seemed lost and in a hurry to finish the test. When I asked her to talk about her drawings while she worked on them, she could not give me any explanation except to describe what she had drawn on the paper. Yoshiko also appeared to not be enthusiastic about the test and appeared to be in a hurry to finish, but was able to describe what was in her mind while taking the test with these words, "Sure I can tell you what is in my mind, I don't have anything in my mind." Other children also appeared to be uncomfortable and unusually still during the test, and Kazu repeatedly asked me what he should do with the materials. Interestingly, it was Kazu who, according to his teacher and my previous observations, was quick to understand academic instructions, thus, it came as quite a surprise that when placed in the pressure of this test environment, he had great difficulty following my instructions.

According to Rogers (1962), it seems that in order for creativity to manifest itself, certain conditions of psychological safety and freedom need to be provided. A good example is Toyo's scores in both creativity tests. Although her score on the TCT-DP was the second lowest, her Drawing Test score was the second highest. This seemed to indicate that when Toyo was in control of an activity such as free drawing, the results of her task would improve.

In summary, although the results of statistical analysis did not find such a relationship between playfulness and creativity in these children, the interpretation of the qualitative data revealed that the playful children were considered to be creative. The group environment with psychological safety and freedom seemed to be related to these children's creativity in this study, and the attributes of playfulness and creativity seemed to have a large overlap.

The concept of internal playfulness and the fact that imagination may be associated with children's internal playfulness came to light during this study. Further research is needed to promote a better understanding of internal playfulness. 
The conditions under which the TCT-DP Test was administered may have influenced the results of the test because it was given to each child in an isolated room and in a nonplayful environment. These children were more familiar with participating in tasks within the context of a group environment.

\section{Personal Reflections}

During the process of writing this dissertation, my main concern was with whether or not I would find anything constructive to contribute to the field of child development. However, the warm support I had been receiving from my committee members, Cosby and Marilyn, inspired me to keep looking. They always encouraged me to continue working because my study would contribute to a western understanding of Japanese early childhood education. Additionally, Marilyn encouraged me to put my personal feelings into my study.

I must tell readers how I felt during the process of doing my research. I am a native of Japan who has been studying child development in this country for almost 15 years. I worked as a preschool teacher in San Francisco for 10 years but have never worked in Japan. My understanding of Japanese preschools and kindergartens comes mostly from my personal observations and from reading western research. The longer I stay in this country, the more my thinking becomes Americanized. In addition to my long stay here, the fact that I have been married to an American for many years has enriched my understanding of the culture of the United States and it has given me a new perspective of the Japanese culture. These are two countries that I care about very much and I also appreciate the many differences between them. I am very interested in the different methods used by each country to educate young children. And it is inevitable that I should understand my study in the context of both cultural backgrounds.

Before I started to collect the data in Japan, the director of Kawasaki Kindergarten, Professor $\mathrm{O}$, who is also a professor of early childhood education, and his associate, Professor $\mathrm{K}$, and I informally discussed the study of playfulness. I welcomed this opportunity as both men have been teaching child 
development for quite some time. Professor K asked me, "What do you think of internal playfulness?" I replied, "What do you mean by that?" Professor $\mathrm{K}$ responded in this way:

You know, some children may be quiet and don't appear to be playful on the outside but that doesn't mean they are not playful...I mean that we should not just think of the child's external behavior or actions in order to assess him or her as playful.

Because I had no answer to his question, I had to ask him again, "Then, how do we measure this internal playfulness?" This time Professor $O$ answered me, saying:

Well, as matter of fact, we don't have an answer for you...but what we wanted to tell you is that studies on play or playfulness in western countries tend to focus on external behavior...we may need to go beyond that to understand children's playfulness. This concept of internal playfulness came to us instinctively.

This discussion turned out to be useful later as the teachers I interviewed described this same internal playfulness, making me realize that my understanding of playfulness had been based on western research.

This discovery of internal playfulness kept me wondering for a long time, and I asked myself why these Japanese educators thought about internal playfulness but I didn't. The reason seems to be related to the morality of the Japanese culture which is based on a sensitivity to the needs and feelings of others. Because of their sensitivity to others, the Japanese people who participated in this study are aware of the child's internal playfulness and see beyond the overt behavior. Because I have been viewing this study from the perspective of the Westerner, it seems that I overlooked the intuitive processes involved in Japanese thinking.

During my stay at Kawasaki Kindergarten, I had various opportunities to talk informally to the director, the assistant director, and the teachers about my study. The head teacher, Keiko, said to me, "It's been interesting to participate in your study because your questions made us think about what we are doing and we feel we've learned something from you." Ms. O, the assistant director, told me that 
it was a good opportunity for everyone to be a part of my study as it stimulated their thinking. She said to me, "I think this was their greatest learning opportunity."

\section{Limitations of the Study}

The first limitation of this study is the sample size. Having only 12 children and six teachers was necessary because the methods of collecting data (the use of tests, interviews, and observations) were time consuming. Generalization of the results of this study if applied to all Japanese children between the ages of 5 and 6 would be questionable because of the size of the sample.

Because of the Japanese indirectness in interactions, another limitation was imposed upon this study. In Japanese culture, it is impolite to directly express your opinions to others, especially to strangers, thus, I kept wondering how comfortable the teachers were talking to me about my questions. This may be one of the reasons that they gave me their written interview responses in addition to oral responses. Additionally, my long term personal friendship with the director and the assistant director of the school had an influence on my way of getting information. I consider myself fortunate to have obtained such rich information and unlimited cooperation from them, but at the same time, I was worried about imposing on them. Although I am a product of Japanese culture, knowing what to ask, when to ask, or how to ask questions did not come easy. Sometimes a particularly close personal friendship in Japan can be strenuous for all concerned. This relates to the issues raised by Catherine Lewis (1986a) when she conducted her research in that country. Perhaps her quotes will explain my feelings of limitation:

..Japanese colleagues who have been too generous in providing me with time, resources, introductions, and so forth. My sense of indebtedness has sometimes inhibited my ability to make requests, to give vertical feedback that a task has been done improperly, and to express disagreement because of fear of conveying a lack of gratitude toward unstintingly generous hosts. My consequent self-censorship has sometimes limited the amount or quality of information I have collected. (p. 195) 
The use of only two tests in measuring the children's artistic creativity created a third limitation. Even though I tried to understand the process of the children's thinking during the TCT-DP Test by asking questions, I was unable to get them to verbalize. Prompts such as, "Tell me the title of your picture." was interpreted by the children as meaning to write their names on the test.

Recommendations for Future Research

A very important suggestion for future research would be to observe children in the context of the home environment, as playfulness relates to one's attitudes toward work, family, and friends (Erikson, 1977). Additionally, it would be useful to observe children during clean-up time. Because cleaning up is considered as work by children, a playful attitude would surface during such an activity.

Since I have become aware of internal playfulness, I would recommend a qualitative study of this specific type of playfulness because it would contribute to the existing literature on the subject. It would be interesting to spend more time with and observe these playful and nonplayful children in terms of understanding internal playfulness.

In order to assess children's creativity, I would recommend the use of participant observation rather than tests. According to the director of the school and another Japanese educational psychologist, Japanese children are trained from early on not to go beyond boundaries, therefore the TCT-DP Test which measures boundary breaking would not be appropriate for Japanese children. A more appropriate measurement of creativity is needed.

Another recommendation would be to conduct a cross-cultural study of the relationship between playfulness and creativity in both American and Japanese young children. Because a review of literature in western countries reveals such a relationship, the comparison of the results of such research will enhance our understanding of playfulness and creativity in terms of cultural differences. 


\section{References}

Acharyulu, S., \& Yasodhara, P. (1984). Assessment of creative thinking abilities of preschool children through spontaneous drawings. Psychological Studies, 29(2), 192-196.

Amabile, T. (1982). Children's creativity: Detrimental effects of competition in a field setting. Personality and Social Psychology Bulletin, 8, 573-578.

Amabile, T., \& Gitomor, J. (1984). Children's artistic creativity: Effects of choice in task materials. Personality and Social Psychology Bulletin, 10(2), 209-215.

Azuma, H. (1986). Why study child development in Japan? In H. Stevenson, H. Azuma, \& K. Hakuta (Eds.), Child development and education in Japan (pp. 3-11). New York: W. H. Freeman and Company.

Bacon, W, \& Ichikawa, V. (1988). Maternal expectations, classroom experiences, and achievement among kindergartners in the United States and Japan. Human Development, 31, 378-383.

Barnett, L. (1990). Playfulness: Definition, design, and measurement. Play \& Culture, 3, 319-336.

Barnett, L. \& Fiscella, J. (1985). A child by any other name...A comparison of the playfulness of gifted and nongifted children. Gifted Child Quarterly, 29(2), 61-66.

Barnett, L. \& Kleiber, D. (1982). Concomitants of playfulness in early childhood cognitive abilities and gender. The Journal of Genetic Psychology, 141, 115-127.

Berg, J. (1989). Qualitative research methods for the social sciences. Boston: Allyn and Bacon.

Boocock, S. (1991). The Japanese preschool system. In E. Beauchamp (Ed.), Windows on Japanese education (pp. 97-125). New York: Greenwood Press.

Cecil, L., Gray, M., Thornburg, K., \& Ispa, J. (1985). Curiosity-exploration-play-creativity: The early childhood mosaic. Early Child Development and Care, 19, 199-217.

Chambers, J. (1969). Beginning a multidimensional theory of creativity. Psychological Reports, 25, 279-799.

Clark, J. (1979). Japan. Illinois: McDougal, Littell \& Company.

Comber, L., \& Keeves, J. (1973). Scientific achievement in nineteen centuries. New York: Wiley.

Cottle, T. (1973). A simple change in creativity. Journal of Creative Behavior, 7(3), 161-164.

Csikszentmihalyi, M. (1988). The future of flow. In M. Csikszentmihalyi \& I. Csikszentmihalyi (Eds.), Optimal experience (pp. 364-383). Cambridge: Cambridge University Press.

Cummings, W. (1980). Education and equality in Japan. Princeton, NJ: Princeton University Press. 
Dansky, J. (1980a). Make-believe: A mediator of the relationship between play and associative fluency. Child Development, 51, 576-579.

Dansky, J. (1980b). Cognitive consequences of sociodramatic play and exploration training for economically disadvantaged preschoolers. Journal of Child Psychology and Psychiatry, 20, 4758.

Dansky, J., \& Silverman, I. (1973). Effects of play on associative fluency in preschool-aged children. Developmental Psychology, 9, 38-43.

Dudek, S. (1974). Creativity in young children--attitude or ability? Journal of Creative Behavior, 8(4), 282-292.

Duke, B. (1986). The Japanese school. New York: Praeger.

Eisner, E. (1982). The contribution of painting to children's cognitive development. Journal of Education, 164(3), 227-237.

Erikson, E. (1977). Toys and reasons. New York: Norton.

Erikson, E. (1972). Play and civilization. In J. Bruner, A.Jolly, \& K. Sylva (Eds.), Play: Its role in development and evolution (pp. 690-703).

Fu, V., Kelso, G., \& Moran, J. (1984). The effects of stimulus dimension and mode of exploration on original thinking in preschool children. Journal of Educational and Psychological Measurement, 44(2), 431-440.

Husen, T. (1967). International study of mathematics: A comparison to twelve countries, Vols 1 \& 2. New York: John Wiley \& Sons.

Gardner, H. (1973). The arts and human development. New York: Wiley.

Guilford, J. (1956). The structure of intellect. Psychological Bulletin, 53, 267-293.

Hendry, J. (1986a). Becoming Japanese. Honolulu: University of Hawaii Press.

Hendry, J. (1986b). Kindergartens and the transition from home to school education. Comparative Education, 22(1), 53-58.

Imamura, A. (1986). Back to basics: The family and the school in Japan. Issues in education, 6(1), $52-64$.

Inagaki, T. (1986). Child development and education in Japan. In H. Stevenson, H. Azuma, \& K. Hakuta (Eds.), Child development and education in Japan. NY: W. H. Freeman and Company.

Iverson, K. (1982). Play, creativity, and schools today. Phi-Delta-Kappan, 63(10), 693-694. 
Japanese Ministry of Education, Science, and Culture. (1982). Preschool education in Japan. Tokyo: the Monbusho Office.

Jellen, H., \& Urban, K. (1986). The TCT-DP (Test for Creative Thinking-Drawing): An instrument that can be applied to most age and ability groups. The Creative Child and Adult Quarterly, 11(3), 138-155.

John-Steiner, V. (1985). Notebooks of the mind: Exploring of thinking. Albuquerque: University of New Mexico Press.

Johnson, D. \& Johnson, R. (1989). Cooperation and competition: Theory and research. Minnesota: Interaction Book Company.

Kinsey, A. (1984). Giftedness and visual language. Gifted Education International, 2(2), 111-115.

Kogan, N. (1983). Stylistic variation in childhood and adolescence: Creativity, metaphor and cognitive styles. In J. H. Flavell \& E. Markman (Eds.), P. H. Mussen (Series Ed.), Handbook of child psychology: Vol. 3. Cognitive development (pp. 630-706). New York: Wiley.

Lanham, B. (1966). The psychological orientation of the mother-child relationship in Japan. Monumenta Nipponica, 21, 322-333.

Levin, J. (1967). Humor in play and sports. In R. Slovenko, \& S. Knight (Eds.), Motivation in Dlay, games, and sports (pp.55-62). Springfield: Charles C. Thomas.

Lieberman, J. (1977). Playfulness: Its relationship to imagination and creativity. New York: Academic press.

Lieberman, J. (1965). Playfulness and divergent thinking: An investigation of their relationship at the kindergarten level. Journal of Creative Behavior, 1, 391-397.

Lewis, C. (1986a). Children's social development in Japan. In H. Stevenson, H. Azuma, \& K. Hakuta (Eds.), Child development and education in Japan (pp. 186-200). NY: W. H. Freeman and Company.

Lewis, C. (1986b). Creativity and Japanese education (Report No. SOO17449). Washington, DC: Office of Educational Research and Improvement. (ERIC Document Service No. ED 271393)

Lewis, C. (1984). Cooperation and control in Japanese nursery schools. Comparative Education Review, 28, 69-84.

Marshall, C., \& Crossman, G. (1989). Designing qualitative research. California: Sage Publications.

Marshall, E. (1986). School reformers aim at creativity. News and Comment, 233, 267-270.

McCracken, G. (1988). The long interview. California: Sage Publications.

Mednick, S. (1962). The associative basis of the creative process. Psychological Review, 69, 220-270. 
Millard, S. (1974). The psychology of play. New York: Jason Aronson.

Moore, A. (1985). Childrearing practices associated with playfulness and Type A behavior in children. Unpublished master's thesis, Virginia Polytechnic Institute and State University, Blacksburg, VA.

Moran, J., Milgram, R., Sawyers, J., \& Fu, V. (1983). Stimulus specificity in the measurement of original thinking in preschool children. Journal of Psychology, 114, 99-105.

Moran, J., Sawyers, J., Fu, V., \& Milgram, R. (1982). Measuring creativity in preschool children (Report NO. PS 013 253). Virginia Polytechnic and State University, Blacksburg College of Human Reproduction Service. (ERIC Document Reproduction Service NO. ED 224 584).

Nagano, S. (1984). Hoikugakuniyumon [Introduction to early childhood education]. Tokyo: Child Books.

Nakagawa, K. (1991). The Japanese and creativity. Illinois Council for the Gifted, 10, 11-13.

Ogawa, E. (1972). Asobi [Play]. In T. Tatsumi, T. Tomomatsu, \& M. Tsumio (Eds.), Handbook of preschool education (pp. 330). Tokyo: Hikarinokuni Books.

Peak, L. (1986). Training learning skills and attitudes in Japanese early educational settings. In W. Fowler (Ed.), Early experience and the development of competence (pp. 111-123). San Francisco: Jessy-Bass INC., Publishers.

Pepler, D. \& Ross, H. (1981). The effect of play on convergent and divergent problem-solving. Child Development, 52, 1202-1210.

Rogers, C. (1962). Toward a theory of creativity. In S. Parnes \& H. Harding (Eds.), A source book for creative thinking (pp. 64-72). New York: Scribner's Sons.

Rogers, C. (1988). Measuring playfulness: Development of the Child Behaviors Inventory of Playfulness. Paper presented at the biennial meeting of the Southwestern Society of Research in Human Development, New Orleans, LA.

Rubin, K., Fein, G., \& Vandenberg, B. (1983). Play. In E. M. Hetherington (Ed.), P. H. Mussen (Series Rd.), Handbook of child psychology (Vol.4) (pp. 693-774). New York: Wiley.

Runco, M. (1989). The creativity of children's art. Child Study Journal, 19(3), 177-189.

Shigaki, I. (1983). Child care practices in Japan and the United States: How do they reflect cultural values in young children? Young Children, 38(4), 13-24.

Shoji, M. (1983). Early childhood education in Japan. In G. Lall \& B. Lall (Eds.), Comparative early childhood education (pp. 48-62). Illinois: Charles C. Thomas Publisher.

Simmons, C. (1990). Growing up and going to school in Japan: Tradition and trends. Philadelphia: Open University Press. 
Simons, C. (1987, March). They get by with a lot of help from their kyoiku mamas. Smithsonian, pp. 44-53.

Singer, J. \& Rummo, J. (1973). Ideational creativity and behavioral styles in kindergarten-age children. Developmental Psychology, 8, 154-156.

Singer, J., Singer, D., \& Sherrod, L. (1980). A factor analytic study of preschoolers' play behavior. Academic Psychology Bulletin, 2, 143-155.

Singleton, J. (1989). Ganbaru: A Japanese cultural theory of learning. In J. Sheilds (Ed.), Japanese schooling (pp. 8-15). Penn: The Pennsylvania State University Press.

Smolucha, L., \& Smolucha, F. (1989). Ego-syntonic aspects of adult play and creativity. Eric Document NO. CG 021800.

Smolucha, F. (1988). Vygotsky's theory of creative imagination and its relevance for contemporary research on play. Unpublished Manuscript, The University of Chicago.

Smolucha, L., \& Smolucha, F. (1986a). L. S. Vygotsky's theory of creative imagination. Spiel, 5, 299-308.

Smolucha, L., \& Smolucha, F. (1986b). The fifth Piagetian stage. Poetics, 15, 475-491.

Starkweather, E. (1971). Creative research instruments designed for use with preschool children. Creative Behavior, 5, 245-255.

Sternberg, R. (1988). A three-facet model of creativity. In R. Sternberg (Ed.), The nature of creativity. (pp. 125-147). New York: Cambridge University Press.

Stevenson, H., Lee, S., \& Stigler, J. (1986). Mathematics achievement of Chinese, Japanese, and American children. Science, 231, 693-699.

Stigler, J. \& Stevenson, H. (1991, Spring). How Asian teachers polish each lesson to perfection. American Educator, pp. 12-20, 43-47.

Tatsumi, T. (1990). Sozoseini michita geijutsuo umidasu yoji [Children who produce creative arts], Doyo, 22, 6-8.

Tegano, D. (1990). Relationship of tolerance of ambiguity and playfulness to creativity. Psycholopical Reports, 66, 1047-1056.

Tobin, J., Wu, D., \& Davidson, S. (1989a). Preschool in three cultures. New Harbor: Yale University Press.

Tobin, J., Wu, D., \& Davidson, S. (1989b). Class size and student/teacher ratios in the Japanese preschool. In J. Shields (Ed.), Japanese schooling. Patterns of socialization, quality, and political control (pp. 59-72). Penn: The Pennsylvania State University Press. 
Torrance, E. P. (1982). Education for "Quality Circles" in Japanese schools. Journal of Research and Development, 15(2), 11-15.

Torrance, E.P. (1980). Lessons about giftedness and creativity from a nation of 115 million overachievers. Gifted Child Ouarterly, 24(1), 10-14.

Torrance, E. P. (1979). The search for satori and creativity. Great Neck, New York: Creative Synergetic Associates.

Torrance, E. P., Reynolds, C., Ball, O., \& Riegel, T. (1978). Revised norms-technical manual for styles of learning and thinking. Athens, GA: Department of Educational Psychology, University of Georgia.

Torrance, E. P. \& Sato, S. (1979a). Differences in Japanese and United States styles of thinking. Creative Child and Adult Quarterly, 4, 145-151.

Torrance, E. P., \& Sato, S. (1979b). Figural creative thinking abilities of United States and Japanese majors in education. Creative Child and Adult Quarterly, 4, 216-221.

Torrance, E. P., \& Torrance, J. (1973). Is creativity teachable?. Indiana: Phi Delta Kappa Educational Foundation.

Vandenberg, B. (1980). Play, problem-solving, and creativity. New Directions for Child Development, 9, 49-68.

Vogel, E. (1979). Japan as number one. Cambridge: Harvard University.

Vygotsky, L. (1930/1990). Imagination and creativity in childhood. Soviet Psychology, 28(1), 84-96.

Wada, M. (1932). Jitsusen hoikugaku [Empirical early childhood education]. Tokyo: Froebel Publications.

Wallace, M., \& Kogan, N. (1965). Modes of thinking in young children. New York: Holt, Rhinehart and Winston.

Ward, W. (1968). Creativity in young children. Child Development, 39, 737-754.

White, M. (1987). The Japanese educational challenge: A commitment to children. New York:

Free Press.

White, M. (1984). Japanese education: How do they do it? The Public Interest, 76, 87-101.

White, M., \& LeVine, R. (1986). What is an ii ko (good child)? In H. Stevenson, H. Azuma, \& K. Hakuta. (Eds.), Child development and education (pp. 55-61). New York: W. H. Freeman and Company. 
Below are some statements describing some chlld behavfors. Please rate oach Item by circling a number on the continuum, with " 1 " being Very Uncharacteristic and " 6 " bolng Very charecteristic.

$\begin{array}{cc}\text { Very } & \text { Very } \\ \text { Uncharacteristic } & \text { Characteristic }\end{array}$

1. Always bas ideas of things to do. ... 1 2 344456

2. Uses props in typical rathor than

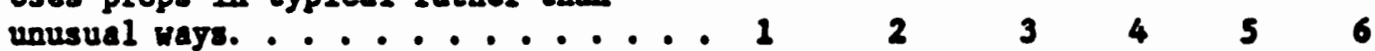

3. Once goal is achleved, stope playing

with the object/material. ....... 1 ... 2 9 $4 \quad 5 \quad 6$

4. Explores different ways to eccomplish

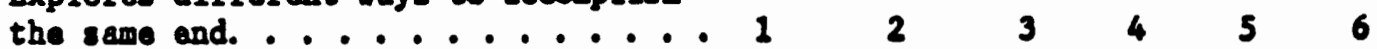

5. Needs reinforcement to continue

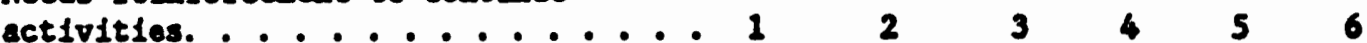

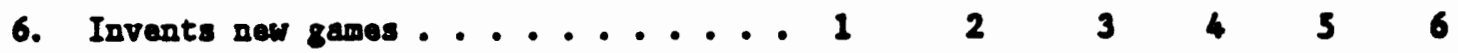

7. Asks many questions about what to do. . $1 \quad 2 \quad 3 \quad 3 \quad 4 \quad 5 \quad 6$

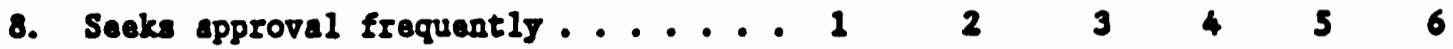

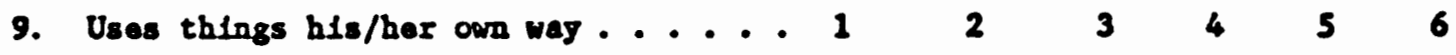

10. Looks to others to tell $\mathrm{him} / \mathrm{h}$ er whet

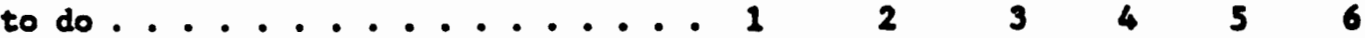

11. Enjoga learning new skills....... 1 2 23445

12. Works woll on his/her-own ....... 1 2 3445

13. Enjoys dolng things oven when there's

no purpose. ............ 1 .... 2 3 4 5 6

14. Has fun dolng things without worrglng

how well they turn out. ........ 1 2. 3 4 5 6

15. Gets so involved in ectivity that it

1s hard to got him/hor to quit. .... 1 2 230436

16. Starts activities for his/her orm

enjoyment. ............ 1 .... 23456

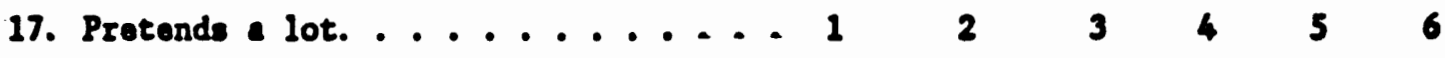


18. Uses toys/objects only in the way they

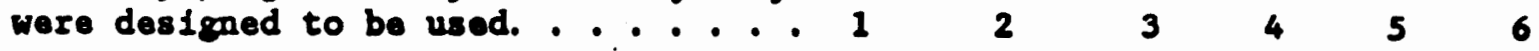

19. Plays eagerly. . . . . . . . . . $1422 \quad 3 \quad 4 \quad 56$

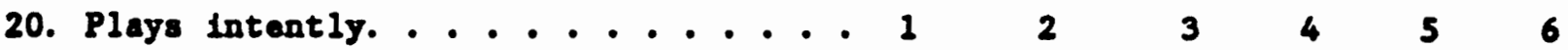

21. Invents varlations on storfes such es different endings or new characters. . $1 \quad 2 \quad 2 \quad 3 \quad 4 \quad 56$

22. Displays axuberance much of the time. - $1 \quad 2 \quad 2 \quad 3 \quad 4 \quad 5 \quad 6$

23. Rearrange stuations to come up with

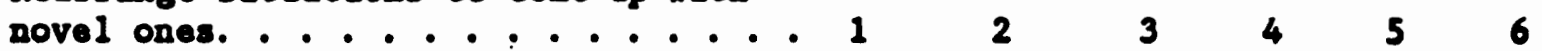

24. Once the ch1ld has been shown bow to do something, he/she creates his/her

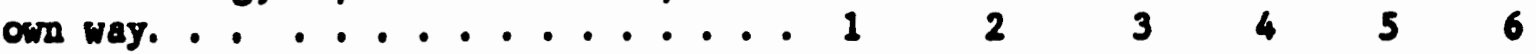

25. Has a sense of humor. . . . . . . . 1 2 $34 \quad 4 \quad 5$

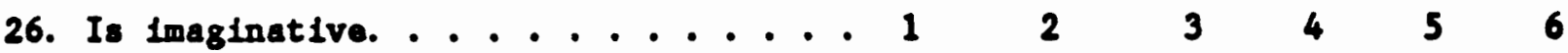

27. Uses toys/objects in unusual ways . . . 1 2 303446

28. Finds unusual things to do with

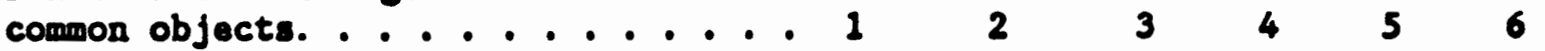

29. Identifies with many characters Instead of playing the same role over agatn . . $1 \quad 32 \quad 3 \quad 4 \quad 56$

30. Gets so involved in an activity that he/she forgets what is golng on in

the room . . . .

$243 \quad 4 \quad 5 \quad 6$

31. Is a playful child. ......... 1

Grade 480 Boy. GIrl 


\section{Appendix A}

\section{CBLin Japanese}

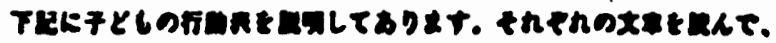

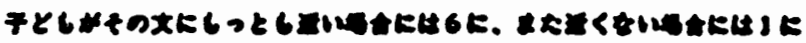
TADetht?

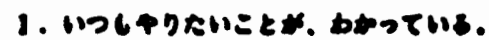

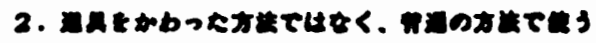

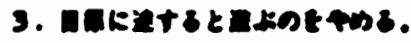

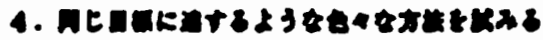

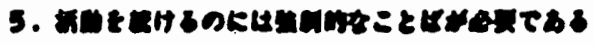

6. ULUY-Atant8

7. जttas theted

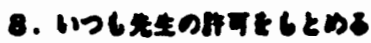

9. nethations

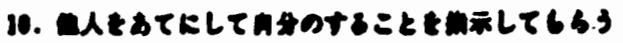

11. mLATELUAHEARSHS

12. AA-ATHATSTAS

13. EL2AnOMUERTSULATPS

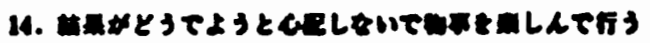

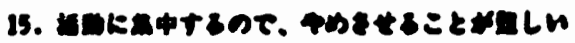

16. Butaseromlatlemos

11. HShtratiets

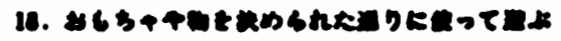

10. Derkints

2. B\&UER⿻十

\begin{tabular}{lllllll}
\hline 11 & 1 & 2 & 3 & 4 & 5 & 6 \\
1 & 2 & 3 & 4 & 5 & 6 \\
1 & 2 & 3 & 4 & 5 & 6 \\
1 & 2 & 3 & 1 & 5 & 6 \\
1 & 2 & 3 & 4 & 5 & 6 \\
1 & 2 & 3 & 1 & 5 & 6 \\
1 & 2 & 3 & 1 & 5 & 6 \\
1 & 2 & 3 & 4 & 5 & 6 \\
1 & 2 & 3 & 1 & 5 & 6 \\
1 & 2 & 3 & 4 & 5 & 6 \\
1 & 2 & 3 & 4 & 5 & 6 \\
1 & 2 & 3 & 4 & 5 & 6 \\
1 & 2 & 3 & 4 & 5 & 6 \\
1 & 2 & 3 & 4 & 5 & 6 \\
1 & 2 & 3 & 4 & 5 & 6 \\
1 & 2 & 3 & 1 & 5 & 6 \\
1 & 2 & 3 & 4 & 5 & 6 \\
1 & 2 & 3 & 4 & 5 & 6 \\
1 & 2 & 3 & 4 & 5 & 6 \\
1 & 2 & 3 & 4 & 5 & 6 \\
1 & 2 & 3 & 4 & 5 & 6 \\
1 & 2 & 3 & 4 & 5 & 6 \\
1 & 2 & 3 & 4 & 5 & 6 \\
1 & 2 & 3 & 4 & 5 & 6 \\
1 & 2 & 3 & 4 & 5 & 6 \\
1 & 2 & 3 & 4 & 5 & 6 \\
1 & 2 & 3 & 4 & 5 & 6 \\
1 & 2 & 3 & 4 & 5 & 6 \\
1 & 2 & 5 & 4 & 5 & 6 \\
1 & 2 & 3 & 4 & 5 & 6 \\
1 & 2 & 3 & 4 & 5 & 6 \\
15 & &
\end{tabular}

21. MEt

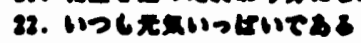

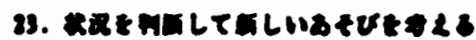

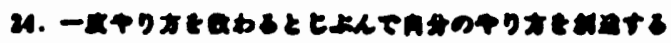

25. $2-z 7 * 85$

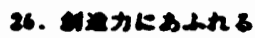

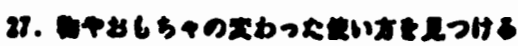

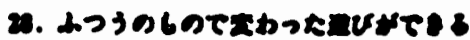

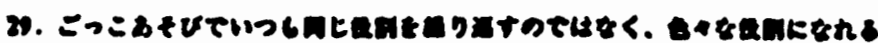

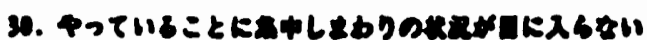

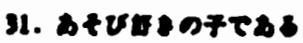

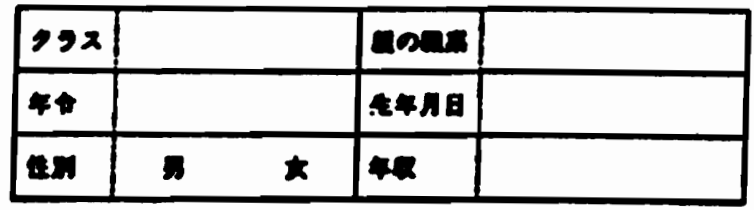


Appendix B

\section{Interview Ouestions for Teachers}

1. What are the most important things for children to learn in preschool?

2. Why should a society have preschools?

3. What kind of experiences should preschool provide?

4. What kind of child are you trying to nurture?

5. What are the most important characteristics of a "good" preschool teacher?

6. What kind of child do you think is playful?

7. Tell me how children's play in preschool should be.

9. How do you define creativity?

10. What do you do to promote children's creativity in the classroom?

11. Do you think you can teach children to be creative? If so, how? If not, why not?

12. I am interested in two children named and in your classroom, tell me about them.

13. Some studies show that playful children may be creative, tell me what you think of these findings.

14. Tell me some things about your classroom that are very unique. 
Appendix C

\section{Questions for Children Taking the TCT-DP Test}

1. When you look at these six shapes, do you see things right away, or do they begin to take shape as you are drawing?

2. Tell me about your picture.

3. Can you tell me why you drew this?

4. What were you thinking when you drew this?

5. Where do these ideas come from?

6. You started on this drawing right away, tell me what made it so easy to start drawing /or/ you took a while to start drawing, tell me what made it so hard to start.

7. Compared to your arts and crafts in school, was this easy for you or difficult? If it was easy, why? If not easy, why?

8. I noticed that you started working on this shape first, tell me why.

9. Tell me the title of these pictures.

10. Tell me if these objects are real or if they are just imaginary. 
Appendix D

\section{Interview Questions for children}

1. Tell me about your favorite things to do in school.

2. Tell me about your least favorite things to do in school.

3. Why do you think you go to school?

4. Tell me about your friend(s) at school. Do you like to play with them or do you like to play by yourself?

5. What do you want to be when you grow up?

6. Tell me about your teacher.

7. What do you do after school? Is your mother home when you get home from school?

8. Do you take any lessons after school?

9. Tell me about your family and yourself. How many people are in your family?

10. What does your father do for a living? What does your mother do for a living?

11. What are your favorite things to play at home? Do you play with someone?

12. Do you play with your parents or your sister or brother at home?

13. Tell me about your favorite TV programs. 
VITA

Satomi Izumi Taylor, a native of Japan, graduated from Meijigakuin University in Tokyo with a B.A. degree in sociology. She was a head teacher in a Pre-K class at Phoebe Hearst Preschool in San Francisco for 10 years. During this period as a teacher, she obtained her M.A. in early childhood education from San Francisco State University. She began her Ph.D. program in August, 1989, at Virginia Polytechnic Institute and State University in Blacksburg, Virginia.

Satomi worked as a head teacher for the laboratory school at Virginia Polytechnic Institute and State University from August, 1989, until April, 1990. She held a research assistantship at the Department of Family and Child Development from August, 1990 until April, 1991. During the 19911992 academic years, she served as Japanese liaison for the assistant dean of the graduate school.

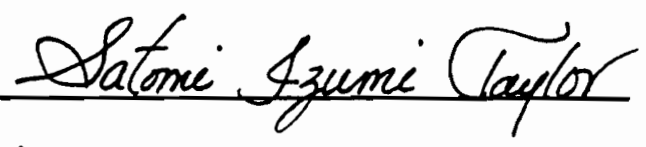

Signature 